\title{
LA CENSURA PEDAGÓGICA DE LA COMPAÑÍA DE JESÚS EN LA EDAD MODERNA A TRAVÉS DE SU REGLAMENTACIÓN JURÍDICA
}

\author{
POR \\ JAVIER VERGARA CIORDIA ${ }^{1}$ \\ UNED \\ Y \\ BEATRIZ COMELLA-GUTIÉRREZ ${ }^{2}$ \\ UNED
}

\section{RESUMEN}

Este artículo analiza el fenómeno de la censura en la Compañía de Jesús en la Edad Moderna. Se abordan dos grandes temas: la opinionum censura y la nostrorum librorum censura. Se estudian cinco frentes documentales: las Observanda circa usum librorum prohibitorum del P. Mercuriano (1575), el breve Exponi nobis del papa Gregorio XIII (1575), el «Procedimiento que los censores de Roma observarán para examinar los libros» [Quae a romanis censoribus observari oportet in censendis libris], aprobado por el P. Acquaviva en 1601, las Regulae Revisorum generalium contempladas en el decreto XI de la X Congregación General (1652) y el análisis de diferentes decretos sobre censura planteados en las Congregaciones Generales de los siglos XVII y XVIII. El material de trabajo se ha extraído del depósito documental sobre el derecho interno de la Compañía, recogido en la edición de Praga de Institutum Societatis lesu (1767).

PALABRAS CLAVE: Compañía de Jesús; censura; jesuitas; Congregación General; libro; colegio de revisores.

\section{PEDAGOGICAL CENSORSHIP IN THE SOCIETY OF JESUS IN THE EARLY MODERN AGE THROUGH ITS DOMESTIC LAW}

\begin{abstract}
This article analyzes the phenomenon of censorship in the Society of Jesus in the Early Modern Age. The research addresses two major issues: the opinionum censura and the nostrorum librorum censura. The work analyzes five documentary sources: the Observanda circa usum librorum prohibitorum of Mercuriano (1575), Exponi nobis of Pope Gregory XIII (1575), Quae a romanis censoribus observari oportet in censendis libris of Acquaviva in 1601, the Regulae Revisorum generalium, decree XI, X General Congregation (1652) and analysis of different decrees on censorship raised in the General Congregations during the seventeenth and eighteenth centuries. The main source of work is the private law of the Society of Jesus, published in Institutum Societatis lesu (1767).
\end{abstract}

KEY WORDS: Society of Jesus; Censorship; Jesuit; General Congregation; Book; School reviewers.

COMO CITAR ESTE ARTículo / CITATION: Vergara Ciordia, J. y Comella Gutiérrez, B. 2017. «La censura pedagógica de la Compañía de Jesús en la Edad Moderna a través de su reglamentación jurídica». Hispania Sacra 69, 140: 545-566. doi: 10.3989/hs.2017.034

$\begin{array}{ll}\text { Recibido/Received } & 15-01-2016 \\ \text { Aceptado/Accepted } & 15-06-2016\end{array}$

\footnotetext{
1 fvergara@edu.uned.es / ORCID iD: http://orcid.org/0000-0002-6118-5905
}

2 bcomell@edu.uned.es / ORCID iD: http://orcid.org/0000-0002-4749-7742 


\section{Planteamiento del PROBlema}

1) El fenómeno de la censura es un método, juicio o evaluación vertical que forma parte de la identidad histórica de la cultura. Puede decirse que ha llegado a todos los resortes importantes del saber, abarcando desde el modo de construcción de ideas, su verificación escrita, así como su control o circulación. Un hecho complejo, que cuando se analiza en el marco de la Compañía de Jesús no puede desligarse de su identidad y de su fin. Estamos ante una institución espiritual de la Iglesia católica, aprobada por Paulo III, el 27 de septiembre de $1540^{1}$, para mayor gloria de Dios y salvación de las almas. ${ }^{2}$ Una institución, a su vez pedagógica, que cifraba su fin en la virtualidad de la unidad triádica fe, virtud y letras. No menos importante es su carácter filológico, que implicaba una relación connatural entre pensamiento, lenguaje y verdad, que le llevó a dominar aquellas lenguas y modelos que mejor la han expresado, a la sazón: latín, griego y hebreo. Finalmente, se trataba de integrar todo el proceso formativo en la mente, en la conciencia y en la libertad personal, pues sin interpretación mental, sin responsabilidad interior y sin autodeterminación no es posible la mejora o formación completa de la persona.

2) Desde esta dimensión entitativa y educativa, que aspiraba a unir la diversidad en el marco de la colegialidad, la Compañía de Jesús diseñó y vivió su apuesta por la censura. Una categoría que afrontó en un doble plano: la llamada censura opinionum, encaminada a la construcción, dirección, verificación e implementación de las ideas y opiniones pedagógicas ${ }^{3}$; y la llamada censura librorum, un intento por afirmar la identidad jesuita mediante la supervisión, vigilancia, juicio y veredicto de la propia producción escrita. El primer aspecto tuvo una dimensión más periférica y descentralizada, se dinamizó desde las realidades colegiales diversas y buscó su realización práctica a través de cuatro cauces pedagógicos: los expurgos, los florilegios, la selección de autores y la experiencia pedagógica acumulada. El resultado fue una teoría censora, recogida en parte en la Ratio studiorum y en diferentes manuales de la época, que ilustró la implementación y verificación de las ideas pedagógicas a lo largo de la Edad Moderna.

3) La censura de los libros fue más centralizada y uniforme. Se concretó en la actualización de cinco frentes. El primero fue el apoyo papal, que alcanzó su zenit con el breve Exponi nobis, firmado el 8 de enero de 1575 por el papa Gregorio XIII, lo que supuso convertir a la Compañía de Jesús en un instrumento censor de primera magnitud al servicio de la Iglesia. En segundo lugar, debe citarse el primer intento por coordinar centralización/descentralización censora,

\footnotetext{
1 Véase en Institutum Societatis lesu. Bullarium et compendium privilegiorum. 1886-1891: vol. III 1-5.

2 Monumenta constitutionum praevia, 1934: 14-21, 24-32, 373$386,422,430$.

3 El concepto de censura opinionum se refiere a la dimensión pedagógica del Humanismo renacentista, dejando de lado todo lo que concierne al concepto amplio de la cultura. Los pedagogos humanistas tenían muy claro este concepto; se trataba de adaptar al signo de los tiempos las ideas y los maestros de la historia. Una exigencia que implementaron con los cauces propios de su época: expurgos, florilegios, selección de autores y experiencia. Dinámica que asentaron en buena parte Erasmo y Vives y que los primeros jesuitas aprendieron cuando vivieron el modus parisiensis en la Universidad del Sena.
}

apuesta llevada a cabo por Everardo Mercuriano, en 1575, mediante las Observanda circa usum librorum prohibitorum. Un tercer frente fue la creación del Colegio Central de Revisores, llevado a cabo por Acquaviva en 1601, medida que significó una apuesta centrípeta por la uniformidad a la que faltó sensibilidad suficiente para reconocer la importancia de la descentralización. El cuarto frente fue el reconocimiento de esa virtualidad, que desembocó en la creación de colegios provinciales de revisores, alentados en la X Congregación General de 1652. Finalmente se recorren distintos decretos de las Congregaciones Generales de los siglos XVII y XVIII, en los que se pone de manifiesto cómo el dinamismo bibliográfico de la Compañía de Jesús desbordó cuando no ignoró la censura oficial de la propia Orden.

4) Todas estas contingencias, que se orientaron a afirmar la identidad jesuita y a proyectarla con ideas y escritos, posibilitaron que la Orden ignaciana produjera uno de los corpus bibliográficos más importantes y selectivos de la Edad Moderna. Carlos Sommervogel, al publicar en 1876 su Bibliothèque des écrivains de la Compagnie de Jésus, ya recogía la cifra de 16224 autores jesuitas que habían producido 52608 títulos. ${ }^{4}$ Una cifra importante, bastante inferior a la real, que convierte a la Compañía de Jesús en una de las instituciones más señeras en la conformación del pensamiento moderno.

5) El material de trabajo que ha permitido elaborar este estudio se ha extraído del depósito documental recogido en la edición latina de Praga de Institutum Societatis lesu (1767). ${ }^{5}$ Un corpus jurídico, de extraordinaria importancia documental, que contiene los principales documentos que han pergeñado el devenir de la censura en la Compañía de Jesús. A ello se ha añadido el estudio de las principales fuentes secundarias. Especialmente relevantes han resultado las investigaciones de Hugo Baldini $(1985,1992)^{6}$, González Novalín $(1990,1994,2001)^{7}$, Fabre $(1995)^{8}$, Lucio Biasiori $(2010)^{9}$ y Doris Moreno $(2013,2015)^{10}$.

6) La amplitud cronológica del tema: 1540-1773 ha favorecido la descripción sistemática de la investigación. Un mayor análisis contextual y hermenéutico hubiera enriquecido las cuestiones planteadas. Pero una demanda de esta naturaleza exigía dos servidumbres insoslayables: por un lado, analizar las cuestiones desde enfoques políticos, religiosos, teológicos y espirituales que exceden el prisma pedagógico de esta investigación; por otro, conocer las censuras concretas de las obras -o al menos una parte importante de las mismas-, su número, su tono, su extensión y su devenir a lo largo del tiempo. Problema complejo, que en parte podrá llevarse a la práctica en un futuro, si se tiene en cuenta que en los anaqueles del Archivum Romanum Societatis lesu (ARSI) se conservan las censuras desde 1550 hasta 1773. Ahí están el nombre de

4 Cfr. Danieluk 2004: 217. Thése de doctoral préparée sous la direcction de M. Claude Langlois, École pratique des hautes études, Section des sciences religieuses.

5 Institutum Societatis lesu, Auctoritate Congregationis Generalis XVIII: MDCCLXVII. vols. II. A partir de ahora se citará Institutum, S.I. Vol. correspondiente y la página.

6 Baldini 1985 y 1992.

González Novalín 1990, 1994 y 2001.

8 Fabre 1995.

9 Biasiori 2010.

10 Moreno Martínez 2013 y 2015. 
los censores, respuestas de los censurados y los puntos concretos que fueron revisados, censurados y expurgados. ${ }^{11}$ Ante la imposibilidad de asumir estas contingencias se ha optado por una sistemática más descriptiva en la que se resaltase globalmente, y casi por primera vez en la historiografía actual, los principales hitos institucionales y jurídicos que han conformado el devenir de la censura en la Compañía de Jesús.

7) Tras este recorrido $-y$ a modo de conclusiónpuede decirse que han quedado reflejados dos hechos palmarios: por un lado, las muchas dificultades por conciliar obediencia, conciencia y responsabilidad en un mundo cambiante y dinámico como fue la cultura moderna; por otro, el extraordinario dinamismo intelectual de los jesuitas y su diversidad colegial difícilmente podía contenerse en los estabulados límites censores de la curia jesuita de Roma. Veamos a continuación cómo se afrontaron estos problemas en sus puntos más significativos.

\section{LA CENSURA DE LAS OPINIONES}

1) La censura opinionum supuso un punto de partida didáctico de la educación jesuita. Una empresa, nada fácil de actualizar, que inicialmente se basó en la pertinencia de los expurgos. Demanda que venía justificada por el modo mismo de construir el discurso pedagógico que tenían los humanistas. Para sus mentores, y los jesuitas en particular, la educación consistía en imitar modelos, en mirar a los maestros de la historia y en sacar lo mejor de su obra para construir otros discursos que redundaran en mayor gloria de Dios, servicio a los demás y mejora personal. Una tarea, de un profundo calado, que exigía limpiar, depurar o purificar los modelos y obras de referencia, librándolas de todo aquello que, a ojos del maestro o expurgador, pudiera considerarse nocivo, erróneo o molesto para el principio irreductible de la Compañía de Jesús: la unidad entre virtud, letras y doctrina.

2) Los jesuitas tenían muy claro esta exigencia, pero realmente no sabían muy bien cómo ejecutarla. Tampoco el humanismo pedagógico tenía una praxis amplia y uniforme al respecto. Téngase en cuenta que los humanistas modernos estaban reinventando la escuela, los programas escolares construyéndose y los libros adecuados eran escasos. En esa tesitura destacan cuatro referencias que empezaron a marcar el sentir de los tiempos. En primer lugar, sobresale Desiderio Erasmo, que fue uno de los primeros en reivindicar una teología o saber elocuente y moral, su Antibarbarorum liber, 1506, su De ratione studii, 1511, y su De copia verborum rerum, 1512, son quizá sus mejores ejemplos. Lo mismo podría decirse de Luis Vives quien, en 1524, al escribir De institutione feminae christianae, o en De officio mariti, publicado en 1529 , estableció todo un canon de los buenos y malos libros. No menos importancia, tuvieron los primeros índices prohibitorios de la Sorbona, aparecidos a partir de $1544 .{ }^{12}$ Aunque quizá el referente más vehemente sea el Theotimus sive de tollendis et expungendis malis libris, obra del benedictino Gabriel Putherbeus, publicada en París

11 Cfr. Baldini 1992: 82-83 Aunque un matiz importante debe reseñarse: apenas se conservan en el ARSI censuras anteriores a 1580.

12 Cfr. Bujanda 1985-2016. en $1548 .{ }^{13}$ Referentes que acertaron a asentar una primera teoría de la censura pedagógica, definida por dos ideas marco: por un lado, lo herético, lo lascivo, lo sentimental o lo puramente profano se presentaba como radicalmente antipedagógico, pues obscurecía lo divino, corrompía la moral y alejaba de Dios; por otro, la excelencia del clasicismo grecolatino debía erigirse como modelo óptimo de elocuencia que había que conservar y desarrollar, pues en sus lenguas y modelos se habían expresado las grandes verdades de la historia de la humanidad.

3) Con este marco se encontraron los primeros jesuitas. Un contexto que conocían perfectamente, pues todos eran hijos pedagógicos del modus parisiensis; pero esto no era suficiente. La Compañía de Jesús necesitaba crear su propia experiencia, validarla, por eso sus primeros colegios fueron un mar de dudas, en cierto modo eran una prueba ad experimentum. Reveladores resultan los interrogantes de Ignacio de Loyola, en 1549, cuando confesaba que algunos clásicos, que se enseñaban habitualmente a los jóvenesTerencio, Virgilio, Marcial, etc.-, contenían elementos útiles para el espíritu, pero también pasajes profanos y deshonestos de los que sólo la lectura sería nociva. ¿Qué hacer ante esta situación? Proponía como alternativa dos tipos de expurgos: bien eliminar las referencias deshonestas y perniciosas de las obras, poniendo en su lugar otras más edificantes, o bien dejar las buenas sin añadir nada que cubriera el vacío dejado por los fragmentos suprimidos. ${ }^{14}$

4) Unos años después, en 1557, las dudas continuaban, estábamos aún en el periodo de consolidación pedagógica de los colegios. El P. Luigi Nappi, profesor del colegio de Padua, preguntaba a la curia jesuita de Roma, cómo conjugar exigencia técnica con exigencia moral. Laínez, sucesor de san Ignacio, respondía casi con sus mismas palabras: la praxis-decía-debía ser despreocuparse de la autoría de las obras y atender exclusivamente a la calidad y exigencia de los contenidos filológicos y morales, aunque introducía una matización importante: los herejes de solidez humanista y científica no debían utilizarse ni comprarse, debiendo ser sustituidos por autores católicos de probado rigor filológico y moral; y concluía, con una prescripción importante: si esto último no fuese posible, podrían utilizarse esos libros aunque borrando el nombre de los autores y las frases inapropiadas. ${ }^{15}$

5) En la medida que el número de colegios aumentaba y la experiencia pedagógica se consolidaba fueron surgiendo nuevas soluciones y alternativas de censura. Una de ellas fue la apuesta por los florilegios. Se trataba de conjuntos de información, sentencias o máximas sobre diferentes temas que, organizados y preparados sistemáticamente por maestros, y consecuentemente expurgados, resumían y presentaban respuestas, complementos y soluciones a preocupaciones y problemas del momento. Esta solución, que tenía una larga tradición, la presentó institucionalmente en 1559 Miguel Torres, visitador de la Provincia de Portugal, al General Diego Laínez aprovechando una publicación

13 Cfr. Gagliardi 2010.

14 Estas dudas aparecen el 22 de junio de 1549, fecha en que Ignacio de Loyola, en una carta a Andrea Lippomani, benefactor de los colegios de Padua y Venecia, confesaba sus dudas para expurgar a los clásicos. Mon. Paed, I: 388- 391.

15 Mon. Lainii, II: 92. 
sobre los epigramas de Marcial. ${ }^{16}$ El resultado fue un banco de datos prefigurado y revisado, un depósito documental seleccionado y variado. Un recurso seguro y pulido que a partir de entonces se consideró básico y sirvió para impartir clases, preparar sermones, ejercicios y discursos que aquilataron y orientaron la preparación de jesuitas y estudiantes a lo largo de toda la Edad Moderna.

6) Un tercer recurso que perfiló la censura opinionum fue la discriminación selectiva de autores. Se trataba de elegir a los maestros, de asentarlos, de rechazarlos o de acomodarlos al temperamento pedagógico de la Orden. El reto no resultaba fácil, planteó interrogantes, retractaciones y dudas. Emblemáticos resultan los nombres de Terencio, Vives y Erasmo. Los tres fueron maestros del mejor clasicismo humanista y los tres fueron utilizados en los primeros colegios de la Compañía para después ser oficialmente reprobados. ${ }^{17} \mathrm{El}$ porqué de esta situación, aunque resulta complejo, está relacionado con las posibilidades reales de hacer efectiva la censura. Parece claro que algunos colegios mostraron resistencias hacia algunas prescripciones que se demandaban desde Roma. En unos casos porque no había forma posible de sustituir o expurgar a los autores citados y su excelencia les hacía acreedores a formar parte del currículum; en otros, por un motivo más sutil: la impresión de obras sin expurgar solía ser un reclamo de proyección. Y algunos vieron en ello un signo de calidad al que no se debía renunciar. ${ }^{18}$

7) Con Terencio, las cosas parecían muy claras desde el principio. En el año 1551, Ignacio encargó una adaptación de sus comedias para ser utilizada en los colegios de la Compañía. El elegido fue André des Freux, profesor de Sagrada Escritura en el Colegio Romano. Una empresa que terminó a fines de 1551 con la prohibición de cualquier lectura y explicación de Terencio en el Colegio Romano por la dificultad de su expurgo. En 1556, Diego Ledesma, siendo su rector, notificaba que poetas como Terencio, Juvenal, Persio, etc., no debían ser autorizados ni para los maestros ni para los alumnos. ${ }^{19}$ Sin embargo, en 1575, la Congregación provincial de España pedía licencia para imprimir en Andalucía a un Terencio expurgado, y el jesuita francés Jouvancy, en 1664, le dio una salida editorial a las Publii Terentii Comoediae ab omni obscenitate expurgatae. ${ }^{20}$

8) Con Vives y Erasmo las cosas no estaban tan claras. El P. Laínez, en 1557, afirmaba en una carta al P. Luigi Nappi, que ninguno de esos autores se encontraba entre los herejes, que la Compañía ni aceptaba los escritos de ambos sin más, ni los había excluido totalmente hasta ese momento. ${ }^{21}$ Sin embargo, a partir de 1558 las cosas cambiaron sustancialmente. Ese año se descubrieron focos de alumbrados en España que produjeron hondas

\section{Mon. Paed, III: 56-57}

17 El caso del colegio de Mesina (1548) es muy significativo. En su segunda clase de gramática se explicaba el De exercitatione linguae latinae de Vives; en el aula de mayores el De octo orationum partium constructione de Erasmo. El Heautontimoroumenos de Terencio, expurgado por Nadal -texto hoy perdido-, fue autorizado en dicho colegio en 1563. Mon. Paed, I: 138, no 11.

18 Fabre 1995: 65.

19 Mon. Paed, II: 741-742.

20 Mon. Paed, IV : 262.

21 Mon. Paed, III: 260-261. preocupaciones. ${ }^{22} \mathrm{El}$ ambiente estaba tan enrarecido que se llegaron a verter acusaciones infundadas de alumbradismo contra algunos jesuitas de renombre -entre otros Francisco de Borja- que llevaron a extremar los cuidados. ${ }^{23}$ Diego Laínez envió al enérgico Jerónimo Nadal a visitar los colegios de la Orden y a definir con claridad la línea espiritual que debían seguir los estudiantes con el fin de que no se pudiera tachar de alumbrado a ninguno de ellos. ${ }^{24}$ Los acontecimientos se precipitaron cuando, en 1559, Pablo IV daba luz verde al Índice de la Inquisición romana, calificado por muchos de un rigor extremo. Fue aquí donde se acusó a Erasmo de iconoclasta e iluminado. Vives inicialmente se salvó, pero poco después fue incluido en los índices inquisitoriales de Venecia (1570/1584), Lovaina-Amberes (1571), y España (1583/1584). Hechos determinantes para que Everardo Mercuriano, IV Prepósito General de la Compañía, prohibiera, el 21 de marzo de 1575, las obras de ambos autores en los colegios de la Orden, dejando al juicio de los prepósitos provinciales la autorización de su uso en casos muy puntuales. ${ }^{25}$

9) El tema de la censura de las opiniones pedagógicas -aunque es amplísimo y susceptible de enfoques diversos- se cerró en buena parte a finales del siglo XVI con las aportaciones de la Ratio studiorum. Un reglamento pedagógico, oficial y común, que empezó a gestarse en 1540 y concluyó sesenta años después con la publicación, en 1599 , de lo que puede considerarse la carta magna de la pedagogía jesuita. ${ }^{26}$ En materia de censura no aportó novedades significativas. Puede decirse que cuando se aprobó casi todo estaba ya dicho y hecho. Con todo, conviene recordar sus recomendaciones dirigidas a los profesores de las facultades superiores sobre cómo conformar ideas y opiniones. Como criterio general, les instaba a comportarse con modestia en cuestiones de libre opinión, no declarando su simpatía por ningún autor; también a que no introdujeran novedades de autores, sino que siguiesen los «mayormente aceptados». ${ }^{27}$ Al profesor de Sagrada Escritura le pedía especial fidelidad a la literalidad de la Biblia, seguir la versión aprobada por la Iglesia (la Vulgata), salvar los dogmas de los pontífices y concilios, seguir a los Santos Padres, y no perder tiempo investigando o refutando a biblistas judíos. ${ }^{28} \mathrm{Al}$ de Teología Escolástica le solicitaba seguir las doctrinas de Santo Tomás, excepto en temas como la concepción de la Virgen, la solemnidad de los votos o cuando resultase ambiguo; y en todos esos casos, le aconsejaba seguir autores de su tiempo, siempre que estuviesen de acuerdo con el sentir de

22 Cfr. Santonja 2001.

23 Cereceda 1950: 174-191, 355-366. Debe hacerse notar que las acusaciones vertidas contra el P. Borja procedían de haberle atribuido obras que no pertenecían a su autoría. Aunque el problema venía de lejos, el propio Ignacio de Loyola sufrió nada menos que cinco imputaciones inquisitoriales: Alcalá (1526), Salamanca (1527), París (1536), Venecia y Vicenza (ambos en 1537) y serias acusaciones formales en Roma (1538) relacionadas con posturas cercanas al alumbradismo, aunque ninguna llegó a término.

24 Cfr. García Hernán 2010.

25 Mon. Paed, IV: 575-576.

26 Uno de los mejores estudios sobre la prehistoria de la Ratio studiorum es el llevado a cabo por Bertrán Quera 1984: 14-56.

27 Ratio studiorum. Reglas comunes a todos los profesores de las facultades superiores. Números 126 y 127.

28 Ratio studiorum. Reglas del profesor de Sagrada Escritura. Números 142, 143, 147, 148, 151. 
la Iglesia. ${ }^{29}$ Finalmente, al profesor de Filosofía se le indicaba que siguiese a un Aristóteles cristianizado, que utilizase sus teorías para engrandecer la fe, y que evitase argumentos o intérpretes del Estagirita contrarios al sentir de la Iglesia. ${ }^{30}$

10) Estas prescripciones, que se engarzaban en las Constituciones de la Orden, en las directrices censoras de la Iglesia católica y en 60 años de experiencia pedagógica, asentaron toda una praxis censora genuinamente jesuita. Algunosmanuales recogieron ese sentir. En primer lugar, debe señalarse el Memorial de algunos apuntamientos tocantes al catálogo de libros prohibidos y expurgados, escrito por el jesuita Diego Álvarez, en torno a 1600. Publicación que orientó a los censores sobre cómo expurgar no sólo obras heréticas, sino aquellas de astrología, ciencia y literatura que fuesen contra el principio de autoridad, marcasen la libertad humana y contradijeran la moral y las buenas costumbres. Sus directrices, en buena parte rigoristas, tuvieron especial efecto en la preparación del Index librorum prohibitorum et expurgatorum de Bernardo Sandoval de $1612 .{ }^{31}$ En la misma línea se sitúa el trabajo del jesuita Jacobo Gretser: De iure et more prohibendi expurgandi et abolendi libros haereticos et noxios, publicado en 1603, en él se exponen argumentos parecidos y sobre todo se intenta reconstruir la historia antigua de la censura para justificar la censura moderna. Sus listas para identificar imprentas y autores heréticos, así como sus consejos sobre cómo expurgar obras literarias lascivas, puramente profanas o que desdijeran las buenas costumbres influyeron sobremanera en el citado índice de 1612. ${ }^{32}$ Finalmente cabe señalar los Erotemata de bonis ac malis libris publicado en 1653 por el P. Thèophile Raynaud, fue un intento por responder consultas y dudas habituales sobre la censura de libros y opiniones.

11) No cabe duda que estos referentes fueron importantes. Generaron un marco de acción directiva para ilustrar a otros jesuitas que, en su papel de inspectores, visitadores o veedores, colaboraron activamente con las inquisiciones locales y las censuras civiles. Especial importancia tiene el caso de Diego Laínez que fue consultor del índice de la Inquisición romana de $1559 .{ }^{33}$ Conocido es el elogio que en 1551 el P. Bautista Sánchez hizo a la función veedora de la Inquisición española al ser nombrado comisionado para la inspección y expurgo de las librerías y bibliotecas de Medina de Rioseco. ${ }^{34}$ El P. Juan de Mariana fue censor de la Inquisición española en acciones tan importantes como la Biblia de Amberes (1578) y la preparación del Índice de libros prohibidos de Gaspar de Quiroga de $1583 .{ }^{35}$ En el siglo XVII, con el apoyo de Felipe IV y la llegada al poder del Conde Duque de Olivares, la

\footnotetext{
29 Ratio studiorum. Reglas del profesor de Teología Escolástica Números 168, 169, 170, 171.

30 Ratio studiorum. Reglas del profesor de Filosofía. Números 201

31 Dicho memorial puede verse en el AHN, Inq., leg. 4435, n. 5. El memorial no tiene fecha, es posterior al índice romano de Clemente VIII (1596), al que se refiere en numerosas ocasiones. Se encuentra, por error, en la documentación que sirvió para la preparación del índice de libros prohibidos y expurgados de Quiroga de 1583/84. Cfr. Bujanda

32 Gretser 1603. Véase una referencia al mismo en Bujanda 2002.

33 Scaduto 1955.

34 Polanci Chronicon, II: 331. Cfr. González Novalín 1990: 42.

35 González Novalín 1994: 101-102.
} 202. 2002. colaboración fue ma-yor. Los jesuitas pasaron de tener dos calificadores en el Santo Oficio a comienzos de siglo a veintiséis a mediados de la centuria. ${ }^{36}$ Una influencia que alcanzó su zenit en 1666, con el nombramiento del P. Everardo Nithard como Inquisidor General, cargo que dejó en 1669 al ser acusados sus ascendientes de extranjería y herejía. ${ }^{37}$ Otros jesuitas tuvieron aportaciones notables. Destacan los casos del P. Juan de Pineda (Índice de 1632), del P. Ignacio de Zulueta (Índice de 1707) y de los PP. José Casani y José Carrasco (Índice de 1747). Los ejemplos podrían multiplicarse, pero en todos aflora un denominador común: las dificultades se resuelven, como les dijo san Ignacio a los jesuitas que participaban en Trento, en el marco de los problemas y mucho más cuando se trata de colaborar con la Iglesia en la transmisión y defensa de la fe. ${ }^{38}$

\section{LA CENSURA DE LIBROS: UN PROBLEMA INICIAL SECUNDARIO}

1) El otro gran apartado que completa la filosofía censora de la Compañía de Jesús es la llamada censura librorum. Una parte menos difusa pero igualmente compleja con la que se trataba de implementar y verificar en lenguaje escrito el espíritu jesuita. De su sentido y pertinencia ya nos dan razón los puntos 273, 274 y 653 de las Constituciones ignacianas. Ahí se sostenían tres ideas fundamentales: en primer lugar, se prescribía que toda publicación interna debía valorarse en Roma por tres personas «de buena doctrina y claro juicio en aquella sciencia» [Cons. 273]; en segundo lugar, se indicaba que lo publicado en materia de lecciones, sermones y libros no debía diferir de lo sostenido por la Iglesia [Cons. 274] y que sólo debía publicarse con el visto bueno del Prepósito General, quien lo hará antes "mirar y examinar» [Cons. 653]; finalmente, y a título de corolario, se apostillaba que la unidad debía presidir el espíritu de las publicaciones: «Y aun en el juicio de las cosas agíbiles la diversidad, quanto es posible, se evite» [Cons. 273]. ${ }^{39}$

2) Las razones que explicaban este planteamiento obedecían a dos hechos de especial relevancia contextual. En primer lugar eran los superiores de las órdenes religiosas quienes por tradición concedían o denegaban el placet a las publicaciones de sus miembros. Su origen data del capítulo general de la Orden de Predicadores, celebrado en París en 1256. Ahí se decía expresamente: «Que ningún escrito hecho o compilado por nuestros hermanos sea publicado de ninguna forma, si antes no ha sido examinado con toda diligencia por nuestros hermanos especialistas, a los que se lo haya confiado el maestro o prior provincial». ${ }^{40}$ En segundo lugar, la censura interna centralizada fue un

\footnotetext{
36 González Novalín 2001: col. 2033

37 González Novalín 2001: col. 2034.

38 Astrain 1912: 517 y ss.
}

39 Cfr. Constituciones de la Compañía de Jesús. Introducción y notas para su lectura. 1993. Arzubialde, S., Corella, J., García Lomas, J. M. (Eds.). Santander: Sal terrae.

40 "Nulla scripta facta vel compilata a nostris fratribus aliquatenus publicentur, nisi prius per fratres peritos, quibus magister vel prior provincialis commiserit, diligenter fuerint examinata». Acta Capitulorum Generalium Ordinis Praedicatorum, 1898:178. Acta Capitulorum Generalium Ordinis Praedicatorum, 1, Ab anno 1220 usque ad annum 1303, 1898: 178. 
mandato expreso del concilio de Trento [1545-1564]. En su sesión IV, celebrada el 8 de abril de 1546, se prescribió que los miembros de las órdenes religiosas debían contar con el permiso de sus superiores para la publicación de sus escritos, amén de la previa autorización, como es lógico, de los órganos censores ordinarios. ${ }^{41}$

3) En los primeros tiempos de la Compañía este fenómeno apenas planteó problemas. Téngase presente que en esos años la Orden no tenía un carácter académico, esto es: enseñar en universidades y colegios; poseía más bien un espíritu misional, orientado a propagar la fe y practicar obras de misericordia. En consecuencia, no estaba bien visto que los jesuitas de primera hora se dedicaran a escribir libros. En este aspecto, resultan gráficas las quejas que mostraba Alfonso Salmerón a su amigo Paolo d'Achille cuando se enteró que había sido impreso su discurso pronunciado en las primeras sesiones del concilio de Trento. Lo consideró poco menos que una afrenta a la sencillez, modestia y humildad de los jesuitas. ${ }^{42}$ El propio Ignacio, en principio reticente a las publicaciones de los suyos, fue evolucionando y a partir de 1550 empezó a apoyarlas para refutar a los herejes y para ayudar a los jesuitas en sus ministerios. ${ }^{43}$ De igual modo, en la primera Congregación General de la Orden, celebrada en 1558 , en su decreto 105 , todavía no se tenía claro si en los colegios debía permitirse la impresión y venta de libros o, por el contrario, debía prohibirse esta práctica para no parecer que se estaba practicando un negocio ajeno a los fines y el espíritu de la Orden. ${ }^{44}$

4) El impulso definitivo de las publicaciones se produjo a partir del 13 de noviembre de 1563, momento en que Antonio Michele Ghislieri, fraile dominico, comisario general de la Inquisición romana (más tarde Pío V, 15661572), concedió a los jesuitas la facultad de editar aquellos libros y artículos que considerasen necesarios para sus casas y colegios. ${ }^{45}$ Hecho importante, que supuso un refrendo al apostolado intelectual de la Orden, una motivación para aumentar las publicaciones internas y la aparición de un problema añadido que hasta entonces apenas había tenido relevancia: cómo evaluar y juzgar las publicaciones de los propios jesuitas. Una función interna que, como otras, los jesuitas solían regular por reglamentos propios que con la experiencia adquirían norma de ley. Pero en el caso de la censura librorum esa posibilidad resultó imposible. Los agentes transversales intervinientes eran muy numerosos, la falta de experiencia acumulada muy palpable y la complejidad del tema, para los tiempos que corrían, manifiesta. Un

41 Concilium tridentinum. Diariorum, Actorum, Epistularum, Tractatuum nova Collectio. 1963-1980: Vol. II: 136 y ss. Friburgi Brisgoviae: Edidit. Societas Goerresiana.

42 M. Sal., 1: 46-47. O’Malley 1999. En el marco de la lentitud gráfica es útil conocer que la primera publicación de un jesuita fue la de Alonso Salmerón, que data de 1547, publicada en Roma y en el mismo año en París: Oratio reverendi patris magistri Salmeronis in Concilio Tridentino habita. In qua ad exemplar divi loannis Evangelistae vera Praelatorum forma describitur. 1547. Romae, Sthepanu Nicolinum.

${ }_{43}$ MI. Epp. 12: 261-262; 9: 116. O’Malley 1999.

44 Institutum Societatis lesu, MDCCLXVII. Vol. II: 181. A partir de ahora se citará Institutum, S. I, Vol. correspondiente y la página. La edición consultada es Institutum Societatis lesu, Auctoritate Congregationis Generalis XVIII, Meliorem in ordinem digestum, auctum, et recursum. Pragae, typis universitatis Carolo Ferdinandae in Collegio Societatis lesu : MDCCLXVII. vols. II.

45 Re. Bul. I: 38. González Novalín 1994: 86. panorama confuso que aconsejó esperar a mejores tiempos. En el ínterin, lo fijado por el incipiente derecho interno, lo recogido en la censura oficial de la Iglesia, y lo impulsado por el magisterio papal debía ser suficiente para evaluar la pertinencia y sentido de las escasas publicaciones internas.

\section{LA CENSURA DE LIBROS EN LAS CONSTITUCIONES Y EN EL MARCO ECLESIAL}

1) El punto de partida de la censura librorum debía ser las Constituciones, en tanto que representan el elemento central que sustancia la naturaleza de la Orden. Se empezaron a definir en 1539 y son esencialmente resultado de la experiencia y el espíritu de san Ignacio. En 1550 estaban muy adelantadas, aunque íñigo de Loyola trabajó en su cierre y pulimento hasta su muerte, acaecida el 31 de julio de 1556. En 1558 fueron aprobadas por la Primera Congregación General de la Orden y confirmadas por Gregorio XIII con la bula Quanto fructuosius (1583). ${ }^{46}$ En materia de censura es especialmente importante su cuarta parte, referida a la instrucción en letras. Ahí se muestra cómo debía ser el perfil de los libros. Una imagen que se resumía en siete reglas ancladas en los principios más señeros del humanismo cristiano de la época:

a) La Constitución 358 decía que toda publicación jesuita debía recrearse en el cultivo y fidelidad a autores y teorías definidos por la solidez de su doctrina intelectual y moral

b) La 359 sostenía que los escritos buscarían siempre crecer moral y culturalmente, evitando libros con contenidos deshonestos y expurgando los que fuesen necesarios

c) La 469 apostillaba que ninguna publicación desligaría saber técnico y saber moral, pues si «algunos -autores- no se pudiesen limpiar como Terencio, antes no se lean".

d) La 359 matizaba que toda publicación debía hacerse para aportar luz, no para alimentar polémicas o sembrar inseguridad, por eso ninguna propagaría o deslizaría dudas, renunciando incluso a publicaciones y estudios de obras cristianas óptimas si sus autores fueran problemáticos, para que «no se le[s] tome afición».

e) La 466 recalcaba que las publicaciones orientadas a optimizar los planes de estudio se caracterizarían por ejecutar con prudencia y «mucho miramiento» la adaptación curricular al sentido y exigencia de los tiempos, procurando que las novedades fuesen las justas y necesarias, "teniendo siempre ante los ojos el fin nuestro de mayor bien universal»

f) Las Constituciones 464 y 466 se referían a los escritos teológicos y defendían que en esa materia toda publicación se definiría por seguir el espíritu sistemático, demostrativo y racional de Pedro Lombardo y Tomás de Aquino. Una praxis que se iniciaba con el apoyo y autoridad del filtro magisterial de la lectio, normalmente basada en fuentes extraídas

\footnotetext{
46 Cfr. Ruiz Jurado 2001.
} 
de la Revelación, clásicos grecorromanos y santos Padres, y culminaba con la aportación hermenéutica de la quaestio o sello personal del jesuita.

g) Finalmente la Constitución 470 , al referirse a los escritos filosóficos, sentenciaba que en los libros de Filosofía se apostaría abiertamente por la Metafísica como principio epistemológico irrenunciable, siendo Aristóteles el modelo a seguir. ${ }^{47}$

2) Éste es el punto de partida del magisterio censor de la Compañía de Jesús. Pero paralelamente a las Constituciones, la censura jesuítica no podía ignorar el magisterio de la Iglesia y mucho menos en un tiempo álgido donde la Reforma protestante había alcanzado con la Paz de Augsburgo de 1555 su reconocimiento oficial. El modelo a seguir fue el Index librorum prohibitorum, aprobado por Pío IV, el 24 de marzo de 1564. Se trata de la obra cumbre de la censura eclesial moderna. Un libro que la historiografía ha bautizado con el nombre escueto de Índice romano. Las Regulae Praefecti Bibliotecae de la propia Compañía de Jesús, aprobadas el 27 de septiembre de 1567, en su punto primero, ya prescribían que dicho índice formara parte obligada del nomenclátor censor de todos los colegios de la Orden. ${ }^{48}$ Un catálogo cuya virtualidad no residía tanto en sus más de mil prohibiciones, sino en las diez reglas que le acompañaban y que habían servido a los padres tridentinos para elaborar sus censuras. Decálogo que por su sentido didáctico se convirtió en referente insoslayable de la censura posterior. Cinco puntos sustanciaban sus preocupaciones:

a) En primer lugar su oposición frontal a todo tipo de herejía, ya fuese antigua o moderna. A tal efecto, se prohibía la lectura, promoción, reedición y publicación de todo libro escrito por heresiarcas antes de 1515, así como la lectura y difusión de cualquiera de escrito de Lutero, Zwinglio y Calvino.

b) En materia bíblica se prohibían las traducciones del Nuevo Testamento hechas por heresiarcas y se establecían restricciones para la lectura y comercialización de la Biblia en lengua vulgar.

c) Se permitían los escritos de herejes, siempre y cuando no tuviesen nada en contra de la religión y mediase la autorización de alguna autoridad eclesiástica.

d) Se establecían especiales restricciones para leer en lengua vulgar controversias entre católicos y herejes relacionadas con la moral, la contemplación, la confesión y otros temas doctrinales de especial relevancia.

e) Finalmente se imponía la prohibición rigurosa de leer libros que tratasen temas lascivos u obscenos, pero no así de autores clásicos por la «Elegancia y propiedad de su lenguaje», para ellos se proponía su expurgo y se recomendaba que no fuesen leídos por los jóvenes. ${ }^{49}$

3) Aunque el Índice romano no se aceptó de forma inmediata en toda la Europa católica, pues algunas Inqui-

47 Cfr. Constituciones de la Compañía de Jesús.

48 Institutum, vol. II: 151-152. Regulae Praefecti Bibliothecae.

49 Cfr. Putnam 2003. siciones nacionales lo consideraban una duplicidad que les llevaba a perder influencia local, fue poco a poco asumido por su sanción papal. Aceptación que se aceleró a partir de 1572, año en que Pío V aprobó la Sagrada Congregación del Índice, órgano permanente de la Iglesia encargado de actualizar la lista de los libros prohibidos o perniciosos para la fe. En la Edad Moderna esta institución llegó a publicar hasta trece índices: tres en el siglo XVI, tres en el XVII y siete en el siglo XVIII. Material de especial trascendencia que la curia central de la Compañía de Jesús debía tener muy presente para dictar con eficacia juicios conforme al sentir de la Iglesia romana. ${ }^{50}$

APOYO DEL PAPADO: EL BREVE EXPONI NOBIS DE GREGORIO XIII Y LAS OBSERVANDA CIRCA USUM LIBRORUM PROHIBITORUM DE MERCURIANO

\section{a) El apoyo del papado}

1) Si las Constituciones ignacianas y los dictámenes inquisitoriales de la Iglesia fueron un referente inicial en la construcción de la historia censora de la Compañía de Jesús no menos importancia tuvo el apoyo y reconocimiento papal. Como es sabido, la Orden nació oficialmente el 27 de septiembre de 1540 y desde ese mismo instante se puso al servicio de la Iglesia para hacer frente confusionismo doctrinal y moral de la época. El papa Paulo III, en una audiencia de 5 de noviembre de 1540, ya concedía a Ignacio de Loyola, vivae vocis oraculo, que determinados jesuitas pudieran leer libros heréticos para hacer frente al peligro protestante. En 1549, les concedía tener trato con los herejes, siempre que se hiciera con intención apostólica. Y, en 1552, Julio III les permitía absolver in foro conscientiae a los que abjuraban de sus errores heréticos. ${ }^{51}$ Unos privilegios que fueron criticados por las Inquisiciones locales, ocasionalmente suspendidos, pero siempre mantenidos y alentados por la mayoría de un papado que vio en la nueva Compañía un baluarte eficaz contra el peligro reformista.

2) Este peligro existía y fue real. Desde 1555 , con la Paz de Augsburgo, el protestantismo se había consolidado y adquirido rango de oficialidad al reconocerse la existencia de otras confesiones cristianas. En ese marco la Compañía estaba recién nacida, tenía todo por demostrar y necesitaba apoyos importantes que consolidaran su posición en el ámbito eclesial. Éstos vinieron de dos papas: Pío V [15661572] y Gregorio XIII [1572-1585]. El primero, cuando sólo era el cardenal dominico Antonio Michele Ghislieri, y en calidad de presidente del Santo Oficio romano, ya concedió a Diego Laínez, sucesor de san Ignacio, tres privilegios que influyeron sobremanera en la emergente dinámica libraria de la Compañía de Jesús. En primer lugar, en 1559, consiguió, vivae vocis oraculo, que no alcanzara a los jesuitas la suspensión del permiso de Paulo IV de poseer libros editados o anotados por herejes; quizás como agradecimiento a la participación del P. Lainez en el índice de la Inquisición romana de 1559, dirigido por Ghislieri; una suspensión que de no llevarse a efecto hubiese significado un duro golpe para sus emergentes bibliotecas, cuyos fondos

\footnotetext{
50 Institutum. S.I. vol. II: 64.

51 González Novalín 2001: col. 2031.
} 
procedían en su mayor parte de imprentas de países reformados. ${ }^{52}$ En segundo lugar, el 13 de noviembre de 1563, confirmó por escrito esa disposición alentando a la Compañía no sólo a poseer sino a criticar, denostar y expurgar activamente las obras escritas y editadas por herejes. Por último, hay que resaltar que dicho escrito conllevaba una apostilla importante: se concedía a los jesuitas la facultad de editar aquellos libros y artículos propios que considerasen necesarios para sus casas y colegios. Un apoyo que permitió impulsar sus imprentas, sus publicaciones internas, a la vez que aumentar considerablemente sus bibliotecas. Privilegio que Ghislieri confirmó, ya en calidad de Papa, el 6 de diciembre de $1568 .^{53}$

3) Su sucesor, Gregorio XIII [1572-1585], intensificó todavía más ese apoyo. Estamos ante un pontífice de carácter firme, optimista, mesurado y tenaz, que hacía gala de dos ideas claras: en primer lugar, que el problema capital de Europa se llamaba protestantismo; en segundo lugar, que ese problema se atajaba potenciando una sólida formación clerical que afirmase la tradición e interpretase en clave católica el sentir de los tiempos. A tal efecto, incentivó la creación de colegios y seminarios para formar cultural y moralmente a los futuros sacerdotes y misioneros de la nueva Europa. Al frente de muchos de ellos puso a la todavía joven Compañía de Jesús, la dotó de nuevos privilegios censores, le dio más autonomía y la convirtió en uno de los principales baluartes de su labor reformadora. ${ }^{54}$

\section{b) El Breve Exponi nobis}

4) La vía que resumía y culminaba ese apoyo fue el breve Exponi nobis, aprobado el 8 de enero de 1575. Un documento que marca todo un hito en la historia libraria de la Compañía de Jesús. Sus cinco puntos fortalecen dos ejes clave de la dinámica censora: por un lado, aspiran a consolidar y convertir la Orden en un instrumento eficaz de la Iglesia romana, unciéndola a las directrices de la recién creada Sagrada Congregación del Índice; por otro, la dotan de una autonomía, amplitud y posibilidades desconocidas hasta entonces. Oportunidad que por su significado y trascendencia se transcribe en su literalidad latino-castellana:

- En su primer punto, ya se concedía al General de la Compañía «compartir la facultad de leer libros heréticos y otros prohibidos, con el fin de atacarlos, mientras se realice con prudencia y discernimiento, y una vez haya sido deliberada la cuestión con sus consejeros». ${ }^{55}$ Una facultad que refrendaba eclesialmente a la Orden, y sobre todo le permitía extender a otros jesuitas, especialmente provinciales y rectores, la posibilidad de leer libros prohibidos para censurarlos y expurgarlos.

- En segundo lugar, se confirmaba que los jesuitas

\footnotetext{
52 González Novalín 1994: 82 y ss.

53 Re. Bul. I: 38 en González Novalín 1994: 86

54 Cfr. Gattoni 2007; Girolami Cheney_2005: 166; Fernández Collado 1991.

55 Institutum, vol. I: 48. Exponi nobis: quod Praepositus Generalis praedictus posset impertiri facultatem legendi libros haereticos et alios prohibitos, ad oppugnandum, dum tamen id considerate fieret et cum delectu, re consultata cum suis Assiestentibus.
}

podrían utilizar libros «no heréticos, aunque tuviesen anotaciones y comentarios de autores heréticos, o bien los propios autores fueran perniciosos, si los libros no habían sido editados para sostener principios heréticos con tal de que el nombre del autor fuera tachado, si fuera hereje $» .^{56}$ Una medida importante que favoreció dotar y ampliar sus bibliotecas con obras científicas diversas, aunque sus imprentas y autores perteneciesen a territorios de iglesias reformadas.

- En tercer lugar, se concedía a la Orden la capacidad de corregir libros de buena doctrina ya fueran de Padres de la Iglesia como San Agustín o San Jerónimo o de autores clásicos como Cicerón pero que «contuvieran comentarios y notas o alguna otra cosa por el estilo, por lo que estuvieran prohibidos, hasta que fueran expurgados una vez tachado, no obstante, el nombre del autor o del impresor malvado». ${ }^{57}$ Apostillas importantes que abrían la Orden a un amplio espectro de obras literarias, morales y teológicas para la que antes existían ciertas dificultades.

- En cuarto lugar, se les reconocía la competencia para expurgar y censurar «no sólo los libros suyos que tuvieran en los colegios o en sus aposentos, sino también los de los estudiantes que acudieran a los colegios de la propia Compañía, cuyos autores morales, aunque por lo demás fueron buenos, estuvieran prohibidos en el Índice a causa de sus comentarios, explicaciones o anotaciones, o por causa del impresor, si fueran designados para esto por el Prepósito General en persona o a través de otros, y que pudieran dejar a sus escolares que los usaran, borrados no obstante los errores y los nombres de los autores prohibidos». ${ }^{58}$

- Finalmente, el breve incluye una absolución completa y total de cualquier pena que con relación a la censura de libros pudiesen haber incurrido los jesuitas en sus correspondientes circunscripciones: «Nos, por tanto, absolvemos al Prefecto General y a los religiosos de cualquier excomunión, entredicho, suspensión y todas las censuras, penas y sentencias eclesiásticas dictadas por el derecho o por vía judicial, sea cual fuere la

56 Institutum, vol. I: 48. Exponi nobis: ac Religiosi dictae Societatis possent uti libris non haereticis, licet haberent annotationes et scholia auctorum haereticorum, vel auctores ipsi mali essent, si libri non essent editi ad stabilienda dogmata haeretica, dummodo nomen auctoris, si haereticus esset vel in Indice prohibitus.

57 Institutum, vol. I: 48-49. Exponi nobis: et si quid inter legendum impium occurreret, deleretur; ipsique a Superiori deputati ad emendandos libros eorum, quid ad ipsos Religiosos vel in scholis vel extra illas recurrere solent, facultatem haberent, quando auctoris boni essent, ut Agustinus, Hieronymus et similes, sed haberent prava scholia vel malas annotationes; aut cum auctor et impressor impii essent, sed non libri; aut cum ethnici exsisterent auctores, sicut Cicero et alii similes, sed haberent scholia, annotationes vel quid eiusmodi propter quod prohibiti essent, donec purgarentur, deletis tamen erroribus et nomine auctoris vel impressoris mali.

58 Institutum, Vol. I: 49. Exponi nobis: nec non quod ipsi Religiosi non solum libros suos, quos in suis Collegiis vel Domibus haberent, sed etiam scholasticorum, qui ad eiusdem Societatis scholas confluerent, quorum auctores ethnici, quamvis alioqui boni essent, sed propter scholia vel annotationes aut commentaria vel impressorem, in Indice prohiberentur, emendare possent, si ad id a Praeposito Generali per se ipsum vel per alios deputati forent, ut suis scholasticis utendos relinquere possent, deletis tamen erroribus et nominibus auctorum prohibitorum. 
ocasión o el proceso que las impuso. Añadimos que, sea cual sea la pena en la que incurrieron $» .^{59}$

5) Con el breve Exponi nobis es obvio que los problemas no se acababan, pero sus cinco puntos ponen de manifiesto que no estamos ante un breve sin más. Estamos, como se ha dicho, ante un primer intento reglado por conexionar desde Roma los intereses censores de la curia jesuita y sus colegios periféricos con los dictámenes de la Sagrada Congregación del Índice. Un propósito loable que lleva a la formulación de una pregunta obvia: ¿podría funcionar esa conexión con las personas, y con los parámetros espirituales y funcionales con los que hasta entonces se desenvolvía la Compañía de Jesús? Para Roma, no. Se necesitaba un cambio de timón y de funcionalidad diferente en la Orden. Los generalatos de Laínez [1558-1565] y Francisco de Borja [1565-1572] se habían dedicado a asentar una Compañía que rezumaba la espiritualidad hispana del siglo xVI, caracterizada pedagógicamente por un dejar hacer al dictamen de la experiencia colegial y al magisterio de la tradición. Un marco en el que la diversidad parecía la nota dominante, ahora se necesitaba convergencia, eficacia, practicidad y sobre todo una unidad de acción que ligase la autonomía colegial al ritmo y a los deseos de Roma.

\section{c) Mercuriano y las Observanda circa usum librorum prohibitorum}

1) Gregorio XIII tenía muy clara esta necesidad. Eran necesarios un nuevo estilo y nuevos dirigentes. La oportunidad de intervenir se le presentó con ocasión de la tercera Congregación General de la Orden, celebrada en 1573. Fue el momento aprovechado por el papa para maniobrar y que saliera elegido nuevo Prepósito General el flamenco Everardo Mercuriano [1573-1580]. La nueva elección no resultaba baladí y significó el fin de la llamada hispanización de la Orden; un cambio muy significativo de personas en la toma de decisiones y el inicio de una política de acción más convergente, práctica y beligerante. El padre Mercuriano era muy consciente de ello. Una circunstancia que en materia de censura supuso convertir a los colegios en verdaderos protagonistas de la misma y uncir su acción a un marco unitario y acorde con el sentir de la Iglesia romana. La vía utilizada fueron las Observanda circa usum librorum prohibitorum. Un documento aprobado el 21 de marzo de 1575 -dos meses después del breve Exponi nobis de Gregorio XIII-, que supuso el primer intento práctico, emanado desde la propia Compañía, por hacer converger centralización jesuita, autonomía colegial periférica y filosofía eclesial censora.

2) El documento consta de un proemio y nueve puntos que -al igual que el breve Exponi nobis-, merecen transcribirse en su literalidad. El proemio contiene dos ideas básicas, orientadas a marcar el fuero de la territorialidad: en primer lugar se trataba de no abordar nada sobre herejías

59 Institutum, vol. I: 49. Exponi nobis: Nos agitur eosdem Praepositum ac Religiosos a quibusvis excommunicationis, suspensionis et interdicti, aliisque ecclesiasticis sententiis, censuris et poenis, a iure vel ab homine, quavis occasione vel causa latis, si quibus quomodolibet innodati exsistunt, ad effectum praesentium dum taxat consequendum, harum serie absolventes et absolutos fore censentes.
- libros heréticos, pues correspondía a «la Santa Iglesia romana» prohibirlos a través de los índices inquisitoriales -o a la censura civil negando la licencia de impresión o circulación-, lo cual evitaba mucho trabajo y una cantidad ingente de problemas; en segundo lugar, se dejaba claro que correspondía a la Compañía dar criterios firmes y unitarios sobre el resto de los libros.

«Conteniendo los libros que están prohibidos por la Santa Iglesia romana, bien herejías, o bien escritos por autores heréticos, que sin embargo no tratan expresamente de religión, o bien están entre los que se leen indecencias, o bien por otro motivo no son en manera alguna convenientes a los nuestros; sobre los primeros, en efecto, en los que hay herejías, aquí nada se trata; pero de los restantes que les siguen hemos considerado que conviene a la mayor gloria de Dios que conforme a la facultad que nos ha sido concedida por la Santa Sede Apostólica, observar lo que sigue». ${ }^{60}$

3) A continuación, y a modo de frontispicio, se introduce una idea capital: las Observanda son una llamada a potenciar la responsabilidad censora de provinciales y rectores. A ellos incumbe, según su criterio y discrecionalidad, y tras consulta con sus consejeros, permitir leer libros de la Compañía a quien juzgaren pertinente. Esta idea puede resultar llamativa, pero no en el contexto de la época. Mercuriano lo único que hace es recordar el tenor del punto siete de las Regulae Praefecti Bibliotecae, aprobadas el 27 de septiembre de $1567 .{ }^{61}$ En ellas se recordaba que correspondía al rector permitir o denegar la lectura de los libros existentes en la casa. ${ }^{62}$ Idea que refuerza el punto dos de las Observanda, donde explícitamente se dice que el Provincial concederá la facultad de leer libros a "los rectores que, ante el Señor, lo estimen más necesario, en función de las ocasiones o de otras circunstancias». Una facultad que, entre otros autores, afectaba a la prohibición expresa de Erasmo y Vives, que son proscritos en el punto tres de las Observanda.

1) «Los Provinciales tendrán la facultad de conceder el uso de todos los libros procedentes de la Compañía a quienes juzguen conveniente, una vez han sido consultados sus consejeros. 2) Podrán los mismos prepósitos provinciales confiar esta facultad de conceder el uso de dichos libros a los rectores que, ante el Señor, lo estimen más necesario en función de las ocasiones o de otras circunstancias. 3) Por otra parte, ya que nos consta qué consideración le merecieron a nuestro Padre Ignacio, de Santa memoria, los escritos de Erasmo y de Luis Vives (por más que tal vez en su época no habían sido prohibidos) nos parece por esto que no se deben tener en una situación distinta en nuestra Compañía, aunque, por lo demás, estuviera permitido hacer uso de ellos. Y así los nuestros se abstendrán de

60 Observanda circa usum librorum prohibitorum. Mon. Paed, IV: 575. (Proemio) Cum qui libri prohibentur a sancta romana Ecclesia aut haereses contineant aut, ab authoribus haereticis conscripti, tamen ex professo de religione non tractent, aut ii sint in quibus obscoena leguntur, aut alia de causa nostris minime conveniant; de primis quidem in quibus haereses sunt, nihil hic agitur; de ceteris vero quae sequuntur iudicavimus ad maiorem Dei gloriam expedire ut iuxta facultatem nobis a Sancta Sede Apostolica concessam, observarentur».

61 Epist. P. Nadal, III: 52.

62 Institutum, II: 151-152. Regulae Praefecti Bibliothecae, 7. Nullum librum ex Bibliotheca cuipiam dabit sine Superioris licentia speciali, aut generali, \& advertat, ne quis librum, etiam cum licentia, se inscio accipiat. 
ellos, excepto si su uso pareciera ser necesario alguna vez a algunos para mayor gloria de Dios, y esto por decisión y con el permiso de los prepósitos provinciales; y para este fin podrán ser guardados en un lugar aparte». ${ }^{63}$

4) En un segundo frente, las Observanda hacen hincapié en la prevención y discriminación de autores vitandos. El punto tres -como ya se ha señalado- presentaba un veto condicionado, pero casi definitivo, a Vives y Erasmo; el cuatro, cinco y seis indicaban las prevenciones con otros autores problemáticos o considerados «indecentes», que serían leídos exclusivamente por los mayores ya formados. En esa calificación se incluían obras de Catulo, Tibulo, Propercio, la mayor parte de los redactados por Ovidio, los de Plauto, Terencio, Horacio, Marcial, Ausonio, Cornelio Galo, la "Propeia» de Virgilio y otros epigramas similares. Autores que "por ningún motivo y bajo ningún pretexto» se permitiría leer a escolares inferiores, o a «maestros sobre los que cupiese duda». ${ }^{64}$ Los Libros eróticos o impuros no debían cederse "absolutamente a nadie». ${ }^{65}$ Con los autores espirituales o piadosos, cuyas tesis fuesen poco afectas a la Compañía: Taulerio, Rusbrochio, Raimundo Lulio, Enrique Suso, etc., debían tenerse especiales precauciones.

5) «No se permita el uso, excepto a los espíritus maduros y a quienes puedan utilizarlos sin peligro y para promover los estudios de las humanas letras, de los libros indecentes, como son los de Catulo, Tibulo, Propercio, la mayor parte de los redactados por Ovidio, los de Plauto, Terencio, Horacio, Marcial, Ausonio y Cornelio Galo. Por otra parte, no les sean permitidos por ningún motivo y bajo ningún pretexto a nuestros escolares, ni tan siquiera incluso a otros maestros, de los que cupiese la duda de que se pueda salpicar alguna mancha contra la pureza, exceptuados, sin embargo, los libros de este género que, o bien ya hubieran sido expurgados o lo vayan a ser en un futuro. Pero han de suprimirse totalmente la "Propeia» de Virgilio y otros epigramas similares. 5). No se cedan absolutamente a nadie todos los restantes libros, en cualquier idioma que estén

63 Observanda circa usum librorum prohibitorum. Mon. Paed, IV: 575. 1) Provinciales habebunt facultatem concedendi usum omnium horum librorum iis qui de Societate sunt, quibus iudicabunt, adhibitis suis consultoribus, convenire. 2) Poterunt iidem praepositi provinciales committere hanc facultatem concedendi usum dictorum librorum iis rectoribus quibus in Domino magis necessarium existimaverint pro ratione locorum aut aliarum circumstantiarum. 3) Cum autem constet quo loco habita sint a Patre nostro Ignatio sanctae memoriae, scripta Erasmi et Ludovici Vivis (licet fortasse nondum eo tempore prohibita essent), propterea nec nobis videntur alio loco in Societate nostra habenda, quamvis alioquin iis uti liceret. Atque ita ab iis nostri abstinebunt, nisi si quibus interdum eorum usus ad maiorem gloriam Dei videretur esse necessarius, idque praepositorum provincialium iudicio atque permissu; quem in finem illa separatim aliquo in loco servari poterunt.

64 Ibídem. Mon. Paed, IV: 576. 1) Provinciales habebunt facultatem concedendi usum omnium horum librorum iis qui de Societate sunt, quibus iudicabunt, adhibitis suis consultoribus, convenire. 2) Poterunt iidem praepositi provinciales committere hanc facultatem concedendi usum dictorum librorum iis rectoribus quibus in Domino magis necessarium existimaverint pro ratione locorum aut aliarum circumstantiarum. 3) Cum autem constet quo loco habita sint a Patre nostro Ignatio sanctae memoriae, scripta Erasmi et Ludovici Vivis (licet fortasse nondum eo tempore prohibita essent), propterea nec nobis videntur alio loco in Societate nostra habenda, quamvis alioquin iis uti liceret. Atque ita ab iis nostri abstinebunt, nisi si quibus interdum eorum usus ad maiorem gloriam Dei videretur esse necessarius, idque praepositorum provincialium iudicio atque permissu; quem in finem illa separatim aliquo in loco servari poterunt.

65 Ibídem. Mon. Paed, IV : 577. escritos, ya en verso, ya en prosa, que contengan asuntos eróticos e impuros. 6) Y ya que incluso entre escritores de libros espirituales, aunque sean piadosos, se encuentran quienes, sin embargo, parece que están demasiado poco de acuerdo con la naturaleza de nuestra Institución, no serán, por esta razón, aceptados sin distinción y al azar, sino solamente por el motivo que se ha expresado más arriba. Tales son Taulerio, Rusbrochio, el «Rosal», Enrique Herp, el «Arte de servir a Dios», Raimundo Lulio, Enrique Suso, las obras de Gertrudis y Matilde, y otros semejantes». ${ }^{66}$

6) Las Observanda se cerraban con un bloque dedicado a la custodia, lectura e inventario de todos estos libros. Categorías en las que el Provincial volvía a adquirir especial protagonismo. Sólo a él incumbía decidir qué libros vitandos o prohibidos se debían de guardar en el colegio, en qué lugar se han de ubicar, cuáles ha de permitir el rector leer a sus subordinados y el tiempo que ha de durar tal permiso. ${ }^{67}$ Se hacía especial hincapié en que ninguno de estos libros se guardase en bibliotecas, aposentos o lugares públicos donde pudieran ser leídos por otros. ${ }^{68}$ Finalmente, los provinciales debían llevar una contabilidad precisa de los libros prohibidos y su ubicación para comunicarla al Prepósito General, amén de las facultades que con relación al tema habían concedido a los rectores.

7) «Por otra parte, no se guardará en ningún lugar de nuestros colegios ninguno de estos libros, si no es de acuerdo con el parecer del prepósito provincial; y al él le corresponderá decidir cuáles y en qué lugares deben ser guardados o cuáles de estos libros deben permitir los rectores a sus subordinados. $Y$, no obstante, no permitirán el uso de estos libros, excepto sólo durante el tiempo que juzguen necesario. 8). Ahora bien, los libros que se permitan a algunos de los nuestros no se guardarán en las bibliotecas ni en lugares públicos o aposentos donde puedan ser leídos por otros. 9). Finalmente los provinciales indicarán al Prepósito General, según la circunstancia, qué libros prohibidos se guardan en cualquier lugar o qué facultad han concedido a los rectores». ${ }^{69}$

66 Ibídem. Mon. Paed, IV: 577. 4) Obscoenorum librorum, quales sunt Catulli, Tibulli, Propertii, plerique ab Ovidio conscripti, Plautii, Terentii, Horatii, Martialis, Ausonii, Galli, usus non permittatur nisi maturis, quique eis sine periculo ad studia litterarum hamaniorum promovenda uti poterunt. Nulla autem ratione scholasticis nostris quocumque praetextu permittantur, ac ne aliis quidem etiam magistris, quorum puritati aliquid labis aspergi posse dubitaretur, exceptis tamen eiusmodi libris qui vel iam expurgati essent aut in posterum expurgarentur. Virgilii vero Priapeia et alia eiusmodi epigrammata aboleantur prorsus. 5) Reliqui omnes libri quocunque idiomate conscripti, sive carmine sive soluta oratione, qui amatoria et impura continent, nemini prorsus concedantur. 6) Ac cum etiam inter scriptores librorum spiritualium, licet pii, inveniantur qui tamen instituti nostri rationi minus videntur congruere, propterea non permittentur passim et sine delectu, sed ea tantum qua superius dictum est ratione. Quales sunt Taulerius, Rusbrochius, Rosetum, Henricus Herp, Ars serviendi Deo, Raimundus Lullus, Henricus Suso, Gertrudis et Mectildis opera et alia huiusmodi.

67 Ibídem. Mon. Paed, II : 577.

68 Ibídem. Mon. Paed, IV: 577-78.

69 Ibídem. Mon. Paed, IV: 578. 7). Nihil vero horum librorum uspiam servetur in nostris collegiis, nisi ex praepositi provincialis sententia; cuius erit decernere quinam et in quibus locis servandi sint, quosve ex his libris rectores suis subditis legendos permittere debeant. Neque tamen permittent usum horum librorum nisi pro eo tempore quo necessarium iudicabunt. 8) Qui autem libri aliquibus e nostris permittentur, non habeantur in bibliothecis, ac ne iis quidem sive publicis locis sive cubiculis ubi ab aliis legi possint. 9) Denique provinciales suo tempore praeposito 
8) Hasta aquí unas observaciones que podrían resumirse en el primer intento serio por una apuesta unitaria de la censura en la que se integraban los deseos de la curia jesuita, el sentir de Roma y el potencial periférico de los colegios. El propósito no cabe duda que era loable, pero no resultaba nada fácil. Téngase presente que en la segunda mitad del siglo XVI el dinamismo cultural era muy importante, se produjo la gran expansión de la Orden y hubo una eclosión de sus colegios por Europa, Asia y América. Realidades vivas, diversas y plurales, que respondían a circunstancias muy variadas, a entornos geográficos muy singulares y a realidades culturales tan diferentes que hacían dificultoso la convergencia y aquiescencia tal como se veía o demandaba desde Roma y desde la propia Compañía.

\section{LA IMPORTANCIA DE LA OBEDIENCIA}

1) Un problema nada fácil de resolver, pues amén de todo ese marco diverso: Roma, curia central jesuita y periferia colegial estaba la conciencia y autonomía del propio jesuita. Su respuesta personal a la Providencia implicaba siempre un respeto a la unidad de la Orden, a la convergencia en la fe, pero también a uno de los elementos más genuinos de su vocación: la libertad de las conciencias. Y a esto un jesuita difícilmente podía renunciar. El elemento que sustanciaba esa interrelación será precisamente la obediencia. Una virtud que se interpretaba como un don especial de Dios, una gracia divina que se aceptaba y se devolvía con un sí sin reservas a la confianza de la Trinidad beatífica y a los directores en tanto que encargados de guiarla y actualizarla para mayor gloria de Dios y provecho de las almas. ${ }^{70}$ Esta máxima, que era un asentimiento de la vocación e implicaba una relación estrechísima entre potestad jerárquica y obediencia ${ }^{71}$, quedó palmaria en dos de los cuatro votos de la Orden. Por el tercero, los jesuitas fortalecían la unidad corporativa. Se trataba de unir a todos y a cada uno de sus miembros con su cabeza y con los superiores a través de un vínculo de obediencia que se fundamentaba en la firme convicción de que a través de ellos Dios canalizaba su voluntad y deseos. Por el cuarto voto se producía una unidad ad extra; se establecía la sujeción y obediencia total al papa, en tanto que vicario y representante de Cristo en la tierra. ${ }^{72}$ Idea clave que implicaba que la Compañía había nacido para servir a la Iglesia y a la voluntad de su cabeza visible: el sumo pontífice.

2) Estas ideas, que estaban en los Ejercicios espirituales, en las Constituciones y en la entraña misma de la vocación jesuita, Ignacio de Loyola las explicó y matizó en sendas cartas e instrucciones que fueron lectura obligada en el refectorio de sus casas, a la vez que documentos base

generali significabunt quinam libri prohibiti in quocumque loco serventur, quamve facultatem rectoribus concesserint.

70 Cfr. Diccionario Histórico de la Compañía de Jesús, 2001: col. 2852.

71 Moreno Martínez 2013: 65.

72 El asentimiento a Cristo comienza obedeciendo «a su verdadero y legítimo vicario en la tierra (...), para que él disponga de nosotros y nos envie a donde juzgue que podremos hacer fruto» (Mon.Const. 1:3). Esta idea, que tenía una larga tradición en el seno de la Iglesia, se fortaleció sobremanera en 1469 con la renovación de la bula In Coena Domini. Paulo II incluía entre sus anatemas el desacato a la autoridad papal, medida que afectaba tanto al poder político como al religioso. para explicar la obediencia en la Iglesia católica de la Edad Moderna. ${ }^{73}$ Tres ideas marco resumían su propuesta. En primer lugar planteó la obediencia como la virtud más útil para llevar a buen término los fines de la Iglesia y de la Compañía, pues sin ella no hay unidad, sólo hay dispersión, fragmentación e ineficacia:

"La razón de esta utilidad es, porque, con ser en toda congregación muy necesaria esta virtud de la obediencia, especialmente lo es en esta, por ser personas de letras los que hay en ella, y ser embiados por el papa y el emperador, y esparcidos en lugares remotísimos de los quales, si la obediencia non fuesse señalada, parece no podia regir tal gente; y assí, ningún ejercicio tengo por más oportuno y necesario para el bien común de la Compañía». ${ }^{74}$

3) En segundo lugar, se recreará en la sumisión al principio de autoridad divina delegada. Al superior -insistirá san Ignacio- no se le debía obediencia por prudencia o por su bondad, sino porque "cuanto el superior ordena es ordenanza de Dios». ${ }^{75}$ Una connotación espiritual que convertía al Prepósito General y a los superiores de la Orden en una causa ejemplar pedagógica de trascendencia extraordinaria.

4) En tercer lugar, sustanció el sentido de la obediencia en tres grados. El inferior era la mera ejecución de lo ordenado, se refería a la obediencia de la acción. A su juicio ésta no era ni siquiera obediencia en sentido estricto. Sólo empezaba a ser virtud en el llamado segundo grado: cuando el ordenado hacía suya la voluntad del superior. El tercer grado, que era el superior y el que marcaba la diferencia, suponía poner la inteligencia, la voluntad y la conciencia al servicio de lo ordenado. Era lo que se ha llamado "obediencia ciega» ${ }^{76}$. Sólo en este grado podía el superior transmitir al ordenado su influjo y su impulso. Sólo aquí se daba la colegialidad vertical perfecta. ${ }^{77}$

«Pero quien pretende hacer entera y perfecta oblación de sí mismo, además de la voluntad es menester que ofrezca el entendimiento, no solamente teniendo un querer, pero teniendo un sentir mismo con su Superior, sujetando el propio juicio al suyo». ${ }^{78}$

5) Con estas explicaciones Ignacio de Loyola dejó claro

73 Monumenta Historica Sociatis lesu (MHSI), Epistolae et Instructiones, vol. IV: 669-681. Las otras cartas: 7 de mayo de 1547, ibídem: vol. I: 495-510; 14 de enero de 1548, ibídem: 687-693. Citado por Moreno Martínez 2013: 66.

$74 \mathrm{MHSI}$, Epistolae et Instructiones, XII, p. 558. Carta de Roma a los jesuitas de Gandía, el 29 de julio de 1547. Citado por Moreno Martínez 2013: 67.

75 «El tercer medio para sujetar el entendimiento es más fácil y seguro, y usado de los santos Padres, y es: presuponiendo y creyendo (en un modo semejante al que se suele tener en cosas de fe) que cuanto el superior ordena es ordenanza de Dios nuestro Señor, y su santísima voluntad, a ciegas, sin inquisición ninguna, proceder, con el ímpetu y prontitud de la voluntad deseosa de obedecer a la ejecución de lo que es mandado", citado por Moreno Martínez 2013: 66.

76 «Hay dos maneras de obediencia: una común, que consiste solamente en obedecer con la voluntad, reservándose su juicio y parezer; otra ay perfecta, que no solamente obedeze con la voluntad mas con el entendimiento, la qual se dize obediencia ciega», MHSI, Epistolae et Instructiones, XII: 662. Citado por Moreno Martínez 2015.

77 Citado por Moreno Martínez 2015: 662.

$78 \mathrm{MHSI}$, Epistolae et Instructiones, XII, 662. Citado por Moreno Martínez 2015: 662. 
cómo obedecer en la Compañía de Jesús. Para él resultaba evidente que la obediencia volitiva e intelectiva -la llamada obediencia ciega- era un acto de libertad autodeterminada, apoyado en la confianza en los superiores y ayudado por la gracia de Dios. Una decisión que lejos de anular la libertad personal o el espíritu de iniciativa, lo impulsaba. El sí jesuita no difuminaba la responsabilidad personal en la acción, tampoco el sello individual y mucho menos la creatividad en la resolución de los problemas. En la obediencia ciega el fin del ordenante y el ordenado coincidían; existía el firme convencimiento que la propuesta de los fines procedía de Dios mismo. Aquí radicaba una de las mayores virtualidades de la vocación jesuita, de la obediencia y de su misterio.

6) Un matiz complejo, no exento de tensiones y dificultades reales, que en ocasiones produjo serias disensiones y conflictos. Los más llamativos se produjeron sobre todo a finales del siglo xvı. Conocido es el caso de los «memo-rialistas». Término con el que se calificó a un grupo de jesui-tas, fundamentalmente hispanos, que, ante los cambios que se estaban produciendo en el gobierno de la Orden tras el nombramiento del P. Mercuriano [1573-1580], consideraron trastocados no sólo sus derechos sino los principios fundacionales de la misma Compañía. Es entonces cuando surgieron críticas aceradas a ciertos aspectos de la obediencia ciega por considerar que iban contra la justicia y la verdad. Conocidas son las críticas mantenidas por jesuitas de la talla de Diego de Santa Cruz, Enrique Enriquez, Juan Ramírez o Julient Vincent, centradas sobre todo en abusos de autoridad y en los problemas de conciencia que ello conllevaba. ${ }^{79}$ Unas críticas de calado que llegaron al mismo papa Sixto V [1585-1590], que no vio con buenos ojos las convulsiones que se estaban produciendo en el seno de la Orden. Un pontífice que quiso dar mayor protagonismo a su pontificado, potenciando la Congregación del Santo Oficio, y limitando muchas de la prerrogativas de las ordenes religiosas, especialmente de la Compañía, que a fuerza de conseguir privilegios de sus antecesores había logrado un margen de independencia y singularidad que en algunos aspectos diluía la autoridad papal. La suspensión del privilegio a la Compañía de absolver en el foro de la conciencia fue una consecuencia de la política papal. ${ }^{80}$ De igual modo las tensiones llegaron a Felipe II que, si bien se mantuvo en un plano expectante, creyó que dichos conflictos procedían de la influencia judeoconversa en la Compañía.

\section{Acquaviva y el Colegio Central de Revisores}

1) ¿Qué hacer ante esta situación? Para evitar buena parte de estos conflictos -que en términos del $P$. Ribadeneira eran los peores por los que había atravesado la Compañía de Jesús desde su fundación ${ }^{81}$-, el P. Claudio Acquaviva, nombrado el 19 de febrero de 1581 V Prepósito General de la Orden, dio un giro de timón hacia posiciones más centrípetas, uniformes y unitarias. Se trataba de eliminar privilegios que obedecieran a carismas nacionales, geográficos, culturales o de singularidad teológica que afectaran a la unidad de la Orden. De igual modo la sintonía con el papado debía ser plena, sin conflictos ni tensiones;

\footnotetext{
79 Cfr. Moreno Martínez 2013: 66.

80 Cfr. Moreno Martínez ibídem: 77.

81 Cfr. Moreno Martínez ibídem: 69.
}

como lo debía ser con las monarquías defensoras de la $\mathrm{fe}$, especialmente la hispana, que estaba en el zenit de su poder. ${ }^{82}$ Para hacer efectivo este giro centrípeto, Acquaviva entró en una especie de prurito reglamentarista que afectó a los puntos centrales del apostolado de la Orden. El plano pedagógico fue una de las primeras fijaciones de esa aspiración. En 1599 aprobó la Ratio atque Instituto Studiorum Societatis lesu. Corolario con el que se cerraba la indefinición pedagógica de la Compañía de Jesús y se abría una nueva etapa caracterizada por una mayor uniformidad en casi todos sus resortes pedagógicos.

2) Uno de ellos fue precisamente la censura librorum, que acabó siendo una auténtica obsesión para el padre Acquaviva. A comienzos del siglo XVII las publicaciones de los jesuitas habían aumentado considerablemente, fruto del aumento de efectivos dedicados a la vida académica. En 1556, dieciséis años después de la aprobación formal de la Orden, el $32,6 \%$ de los jesuitas se dedicaban a la enseñanza en los 46 colegios que disponían. En el primer tercio del siglo XVII, la cifra se había disparado hasta alcanzar las 400 instituciones, ocupando en la docencia al $42 \%$ de los efectivos de la Orden. ${ }^{83}$ Un aumento considerable que tuvo una traducción libraria extraordinaria. En 1608, cuando Pedro Rivadeneira publica en Amberes la primera historia bibliográfica de la Compañía de Jesús: Illustrium scriptorum religiones Societatis lesu catalogus, las cifras son muy elocuentes. La obra ya muestra una nómina de 260 escritores jesuitas, con un millar de títulos, repartidos en 24 unidades temáticas, en las que prevalecen temas bíblicos, la teología escolástica, moral y pastoral, la filosofía, los sacramentos, los catecismos, vidas de santos, la gramática grecolatina, la oratoria y un pequeño apartado para las matemáticas.

3) Un hecho que por sí mismo constata la enorme capacidad publicista y escritora de la Compañía de Jesús. Realidad que Acquaviva quiso centralizar y normativizar para hacer efectivo el anhelado punto 273 de las Constituciones ignacianas, donde se prescribía que la unidad debía presidir el espíritu de las publicaciones: «Y aun en el juicio de las cosas agíbiles la diversidad, quanto es posible, se evite,» [Cons. 273]. El tema no cabe duda que preocupaba en exceso a Acquaviva. En sendas cartas dirigidas a los provinciales y fechadas el 18 de enero de $1597^{84}$ y el 19 de octubre de $1598^{85}$ manifestaba que, por la diversidad geográfica de las provincias, por la diversidad de juicio en los revisores, por la variedad de colegios y por el escaso rigor mostrado por los provinciales, se había desembocado en una falta de rigor y convergencia censora que dañaba el espíritu de obediencia y la anhelada unidad de la Orden. Un grave problema que podría resolverse, según carta fechada el 12 de enero de 1599, creando en Roma un colegio estable de

82 La V Congregación General de la Orden, celebrada en 1593, fue sintomática al respecto. Los congregados acordaron no hacer uso de los privilegios papales que la Compañía tenía en España para no molestar al monarca, de igual modo contentaron al sector interno de la Compañía partidario de la «limpieza de sangre» para castigar al movimiento memorialista; ratificaron la colegialidad vertical y jerárquica de la Orden y refrendaron la sumisión a la autoridad papal. Cfr. Moreno Martínez Ibídem: 64 .

83 Para un seguimiento de los efectivos jesuítico-docentes consultese: Lukács 1958; 1960 y 1961.

84 Véase el estudio que al respecto realiza Moreno Martínez 2013: 69-76.

85 Archivum Romanum Societatis lesu (ARSI), Insti. 41, ff. 123 v-4. 
revisores, regulado por normas claras y precisas, y conformado por personas sólidas y reputadas en las diferentes ciencias. ${ }^{86}$

4) La decisión estaba tomada y los acontecimientos se sucedieron con rapidez. El 23 de junio de 1601, el Colegio Central de Revisores era una realidad. Ese mismo día, Bernardo de Angelis, secretario de Acquaviva, daba a conocer el «Procedimiento que los censores de Roma observarán para examinar los libros» [Quae a romanis censoribus observari oportet in censendis libris]. ${ }^{87}$ En principio, el colegio se compondría de cinco miembros: uno por cada una de las Asistencias de Italia, España, Francia, Alemania y Portugal. Un miembro presidiría el Colegio y otro haría las veces de secretario. El nombramiento de revisor tenía carácter indefinido, estaba adscrito al Colegio Romano, y su estatus se situaba después de los superiores de Provincias. Sus decisiones no tenían carácter vinculante, sino consultivas, su misión sería ayudar al P. General a decidir sobre la publicación o rechazo de los manuscritos internos de la Orden. ${ }^{88} \mathrm{El}$ número e identidad de los revisores centrales desde 1551 a 1773 puede verse en el llamado fondo de la iglesia del Gesù de la Biblioteca Nazionale Centrale Vittorio Emanuele de Roma. ${ }^{89}$

5) El documento era muy escueto. Se sustanciaba en cuatro reglas claras, concretas y precisas, que rezumaban un marcado acento centrípeto. Su primer punto se refería al número de censores y al tipo de obras a examinar. Se contemplaban dos censores cuando se tratase de obras sobre historias profanas, letras humanas o similares, no siendo necesario que consultaran toda la obra; sería suficiente que cada uno examinase alguna parte y después hubiese un contraste de pareceres. Cuando el contenido se refería a la Sagrada Escritura o a temas morales con un enfoque especulativo, escolástico o controvertido, se requería la presencia de los tres revisores y el examen completo de la obra:

\begin{abstract}
1) Romani Censores in recognoscendis Libris modum hunc servabunt: si qui eorum sunt qui historias tantum profanas litte-rasve humaniores, aut similia tractant, satis erit, ut singuli partem aliquam operis inspiciant, ac inter se postea conferant, sed non pauciores duobus integrum opus evolvere debent. // Si argumentum ad Sacras Litteras, morumque doctrinam spectet, quod si in rebus speculativis, sive scholasticis, aut in controversias versetur, necesse erit, ut a tribus saltem perlegatur, quandoquidem singulorum censurae ab universis legi et expendi debent.//
\end{abstract}

1) «Los Censores de Roma observarán este procedimiento para examinar los libros: si hay algunos de estos que tratan tanto historias profanas como letras humanas o similares, sea suficiente que cada uno examinen alguna parte de la obra y después las contrasten, pero no menos de dos deben leer la obra completa.// Si el contenido se refiere a las Sagradas escrituras y a la doctrina moral, pero que verse sobre cuestiones especulativas, o escolásticas, o sobre controversias, será necesario que sea leído enteramente por lo menos por tres (censores) ya que las censuras de cada uno de ellos deben ser leídas y sopesadas por todos».

6) El segundo punto regulaba la publicación o rechazo de la obra. El veredicto se tomaba por mayoría de votos y

${ }_{86}$ ARSI, Instit. 46, fol. 46 v. Cfr. Baldini 1992: 108. ARSI, Epistolae Nostrorum, T. 116, Epistolae comunes (1645-1727), Romae: 161-162.

87 Quae a romanis censoribus observari oportet in censendis libris. Transcritas en Baldini 1992: 85.

88 ARSI, Rom 2, ff. 56r-57v. Cfr. Baldini 1992: 109.

89 BNVE, FG 1666. Cfr. Baldini 1992: 108. se hacía acompañar de las observaciones de los revisores y de las correcciones que demandaban. En el veredicto se tenían en cuenta los juicios de las censuras provinciales y se sopesaba si merecía la pena trasladar los juicios al autor. Cuando así se hacía, éste podía replicar en primera instancia. La decisión última sobre publicación o rechazo correspondía al P. General. ${ }^{90}$

2) Duo item observanda erunt.// Unum ut dispiciant an liber talis berán ser observadas.// Primero, sit, qui in lucem edi iure possit, que miren que el libro es de tal quod quidem iudicium sive inter valor que, en justicia, pueda ser se consentiant, sive discrepent, publicado, juicio sobre el que, una cum oppositis rationibus, si ya estén de acuerdo entre ellos, quae ipsis in contrarium occurant, ya discrepen, lo trasladarán al P. referent ad Patrem nostrum, General junto con las consideracuius erit diiudicare et componere ciones opuestas, si algunas concontroversiam.// Alterum ut curriesen en contradicción para si postquam a deputatis, quo ellos, a quien corresponderá juzgar modo dictum est, inspectus y conciliar la controversia.// Segexaminatusque fuerit, operae undo, que, si después de que ha Premium duxerint, ut edatur, sido examinado e inspeccionado definiatur pariter a maiori eorum el libro, del modo que se ha dicho, parte, an corrigi liber debeat,iuxta por los censores designados, ellos censuras, tum Provinciae, tum consideran que merece la pena Censorum ipsorum Generalium, que sea publicado, se determine quorum quidem censurae, ac por la mayor parte de estos (los iudicia auctori ostendi, necne, ex censores), si el libro debe ser cor$P$. nostri prout expedire magis ei regido, en función de las censuras, visum fuerit, arbitrio pendebit, qui tanto de la provincia como de los omnibus expensas, id statuet, quod propios censores generales, a los in Domino visum fuerit. que pertenecen las censuras, y si los juicios deben ser mostrados al autor, y ciertamente la medida en que le parezca mejor resolverlo dependerá del juicio que proceda de nuestro P. General, quien examinado todo, decidirá lo que le parezca bien en el Señor».

7) El tercer punto era, con mucho, el más importante: definía el marco de actuación. Se contemplaban cinco frentes o criterios de censura.

a) En primer lugar, lo prescrito en las reglas 5 y 6 de la Ratio, referidas a los profesores de las facultades superiores, a quienes se exigían dos normas básicas: primero, comportase con modestia cuando emitiesen cuestiones de libre opinión, no declarando su simpatía por ningún autor; segundo, no introducir novedades de autores sino seguir los «mayormente aceptados».

b) En segundo lugar estaban los temas referidos a la Sagrada Escritura. Los censores debían considerar la adecuación de los trabajos a las reglas 1, 2, 6, 7, $8,9,10,11$ de la Ratio. Ahí se pide que el profesor de Escritura Sagrada tenga especial cuidado con la literalidad de la Biblia, siga la versión aprobada por la Iglesia (la Vulgata), salve los dogmas de los pontífices y concilios, siga a los Santos Padres, y no pierda tiempo investigando o refutando a biblistas judíos.

\footnotetext{
90 Quae a romanis censoribus observari oportet in censendis libris.
} 
c) En tercer lugar se pedía mirar las reglas 2, 3, 4, 5 del profesor de Teología Escolástica, quien debía refrendar las doctrinas de Santo Tomás, excepto en temas relacionados con la concepción de la Virgen $^{91}$, la solemnidad de los votos o cuando el Aquinate resultase ambiguo; en esos casos se aconsejaba seguir autores de su tiempo.

d) Finalmente, en los temas de filosofía los censores debían fijarse si se cumplían las reglas 2 y 3 de la Ratio. Expresamente se pedía que se siguiera a un Aristóteles cristianizado y que se utilizaran sus teorías para engrandecer la fe; en modo alguno debían utilizarse argumentos o cultivarse intérpretes del Estagirita contrarios a la religión.

e) A título de corolario se pedía no escribir nada contrario a la doctrina cristiana, cosas que pudieran ofender con razón a otros, que pareciesen inconvenientes a la gravedad religiosa y que faltaran a la prudencia propia de la Compañía. ${ }^{92}$

3) Censura horum librorum, quae in Urbe ad Inspectoribus fiet, consentanea iis esse debet, quae in Regulis Praeceptorum facultatum superiorum, videlicet 5, 6 et Professoris Scripturae 1, 2, 6, 7, 8, 9, 10, 11, et Professoris Scholasticae Theologiae 2, 3, 4, 5 et Professoris Philosophiae 2, 3 praescripta sunt, soliditatem, uniformitatemque doctrinae iuxto Constituciones nostras praecipue semper intuendo, et iuxta decretum 55 Congregationis. //Atque in universum loquendo, non solum admitti nihil debet, quod fidei nostrae, pietatisque christianae non prorsus congruat, id enim certum esse debet, sed neque aliud quicquam, quod alios merito possit offendere, aut gravitatem Religiosam, iustamque Societatis nostrae circumspectionem dedecere videatur.

3) «La censura de estos libros que se haga en Roma por los Inspectores, debe estar de acuerdo con las que hayan sido dispuestas en las reglas de los preceptos de las facultades superiores, sobre todo la 5 y 6 , también en las reglas $1,2,6,7,8,9,10,11$ del profesor de Sagrada Escritura, en las reglas 2, 3, 4, 5 del profesor de Teología Escolástica y en las reglas 2 y 3 del profesor de filosofía, siempre sin olvidar la solidez y uniformidad de la doctrina, junto con nuestras Constituciones y también el decreto 55 de la Congregación. Y hablando en general, no sólo no debe ser admitido nada que no sea totalmente congruente con nuestra fe y la piedad cristiana, esto ciertamente debe ser seguro, ni tampoco cualquier otra cosa que pueda ofender con razón a otros, que parezca ser inconveniente a la gravedad religiosa y a la justa prudencia de nuestra Compañía».

8) El último punto, no menos importante, se refería a la recepción y destino de las obras. Todo manuscrito debía llegar a los censores por vía del P. General o de su secretario. El original se devolvía añadiendo el año con la censura anotada y firmada. A nadie debía mostrarse sin el permiso del P. General. Los libros debían examinarse en el orden en que eran entregados, no revisando más de una o dos obras a la vez, para así evitar confusiones y dilaciones en la entrega..$^{93}$

91 El tema de la concepción inmaculada de María fue un tema estrella de la mariología del siglo XVı en España. Un tema que contrastaba con ciertas posiciones tomistas. Para evitar polémicas y dudas, la Congregación General V, 1593/94, en su decreto 41, estableció separarse de las tesis del Aquinate en ese tema puntual y seguir la corriente hispana de su tiempo. Institutum. S.I. Vol. I, Cong. V, Decr. XLI, I: 553.

92 Quae a romanis censoribus observari oportet in censendis libris.

93 Ibídem

Hispania Sacra, LXIX

140, julio-diciembre 2017, 545-566, ISSN: 0018-215X, doi: 10.3989/hs.2017.034
4) Nullum Librum Scripturamve a quoquam recongnoscendum accipiant, praeterquam a P. N.Generali aut eius nomine a P. Secretario, singula deinde recognita eidem reddent, cum censura uniuscuiusque manu, die, annoque adscriptis, subnotata e obsignata. Porro nec censuram hanc, nec scripta, quae recensent, priusquam edantur cuique ostentent sine P. Nostri facultate, secreti studium, quod eis in hoc munere plurimum commendatur, reipsa declarantes. Singula sibi commissa ordine, quo a P. Secretario tradentur, examinabunt, nisi aliud interdum P. Nostro videatur, nec plusquam unum, alterumve opus, inspiciendum simul aspicient, ut vitetur perturbatio, citiusque expediantur, quae priore loco ipsis commissa sunt.

\section{REVISORES}

1) La puesta en marcha del colegio central de revisores no sólo puso al descubierto el deseo de hacer viable la diversidad en el marco de la unidad. Reconocía también la existencia de un dinamismo creativo, pluralidad de ideas, matices y sentimientos diferenciados que generaban conflictos a los que había que dar respuesta. ${ }^{94}$ De hecho, los problemas siguieron existiendo y en algunos casos se agudizaron. Era palmario que el aumento extraordinario de publicaciones exigía mayor capacidad de respuesta, que la diversidad multicultural y científica exigía mayor amplitud de miras, que las dificultades de comunicación con ultramar y las largas distancias posibilitaban la tardanza, el retraso, cuando no la pérdida de obras. Un largo etcétera de inconvenientes que empezaron a suscitar otras soluciones y alternativas que supiesen interpretar el signo de los tiempos..$^{95}$

2) España y Portugal abanderaron buena parte de estas quejas, planteando como mejor solución la desconcentración y descentralización censora en favor de las provincias. Una reivindicación latente que por su insistencia y autoridad surgió efecto. En 1604 Acquaviva accedió a que los jesuitas de España y Portugal pudieran censurar sus libros en sus propias provincias sin necesidad de acudir a Roma, excepto cuando se tratase de obras controvertidas sobre la gracia, las que abordasen temas sobre jurisdicciones eclesiásticas y aquellas que no tuvieran una clara fundamentación en la filosofía del Aquinate y del Estagirita. ${ }^{96}$ Para el resto de publicaciones, debían censurarse en sus propias provincias y seguir lo prescrito por el Colegio Central de Revisores.

94 Cfr. Matei y Casalini 2014. Los autores de esta obra plantean como una constante de la Orden jesuita el dinamismo tensional entre la convergencia y la libertad individual.

95 Biasiori 2010.

$96 \quad$ ARSI, Opp. NN 115, 298. 
3) La extensión de la desconcentración a otras provincias no fue posible. La muerte del P. Acquaviva en 1615 paralizó cualquier intento al respecto. La consiguiente Congregación General (1615/1616) que siguió a su óbito -la VII-, aparcó el problema. Sus congregados, en su decreto 84, limitaron su trabajo a tres temas librarios de gran trascendencia: en primer lugar, dieron permiso para que los libros editados en las imprentas de los jesuitas o a instancias de la Orden se vendieran fuera de los $\operatorname{colegios}^{97}$, en segundo lugar, se advirtió que comerciar con libros no era propio de un jesuita y que estaba terminantemente prohibido ${ }^{98}$, finalmente recordaron el mandato expreso de pedir licencia para publicar libros. Felipe IV, en 1626, ya se hacía eco de este problema, que no era pequeño y circunstancial, por lo que exigía que todo libro escrito o traducido por un jesuita o regular debía llevar la licencia previa de sus superiores y del ordinario del lugar donde residieran. ${ }^{99}$

4) El P. Mutio Vitelleschi, sucesor del P. Acquaviva, en sus treinta años de generalato [1615-1645], calmadas las demandas de España y Portugal, no modificó la reglamentación y dejó que las cosas siguiesen su curso. A su muerte, acaecida el 9 de febrero de 1645, le sucedió Vicenzo Carafa [1645-1649], que fue elegido nuevo Prepósito en la VIII Congregación General, 1545/1546. En su decreto LVII, los congregados, trataron el tema de la desconcentración, pero se limitaron a anunciar la creación de una comisión que con nuevas reglas recondujeran el problema. ${ }^{100}$ La siguiente Congregación, la IX, 1649-1650, apenas pudo aprobar nada. El corto gobierno de su Prepósito General, Francisco Piccolomini [1649-1651], simplemente sirvió para convocar la X Congregación General, que se celebró en los tres primeros meses de 1652 . Un periodo suficiente en el que los congregados sí pudieron trabajar. ${ }^{101} \mathrm{En}$ su decreto $\mathrm{XI}$, aprobaron 15 reglas que asentaron la praxis censora de la Compañía para todo lo que restaba de la Edad Moderna. ${ }^{102}$

5) En la práctica, las 15 reglas validadas en la $X$ Congregación no supusieron un cambio cualitativo en la censura jesuita. Fueron sobre todo una desconcentración y reforzamiento ampliado y aumentado de lo elaborado por Acquaviva en 1601 para confirmar el espíritu o colegialidad vertical de la Compañía de Jesús. Una apuesta que descansaba en dos ejes nucleares: en primer lugar, se afirmaba la necesidad de mantener un colegio central de revisores, llamado a garantizar la unidad y convergencia de la totalidad de escritos de la Compañía de Jesús, y especialmente de aquellos referidos a la gracia, la teología

97 Typographiam in Collegiis habere, in qua libri excusi externis divendantur. In utraque tamen India partibusque septentrionalibus, pro libris piis et ad religiones spectantibus scholarumque nostrarum, cum vel typographi desunt, vel catholici desunt, iudicio Patris nostri rem totam committendam censuit (Institutum. S.I.vol. I: 608).

98 Typographiae sumptus pro edendis Nostrotum libris suppeditare, exemplaque damno lucroque nostro divendenda accipere. Quae res, licet absolute negotiatio clericis interdicta non sit, Nostris tamen videtur omnino interdicenda, nec nisi gravísimas ob causas a Patre nostro permittenda». (Institutum. S.I.vol. I: 608).

99 Novissima Recopilación, Libro VIII, título XVI, ley VIII, 126.

100 Institutum. S.I. vol. I, Cong. VIII, Decr. LVII, Sess. 128.

101 Institutum. S.I. vol. II, Regulae, qua a Patribus Revisoribus generalibus Romae in recognoscendis nostrorum libris, ac scriptis observandae sunt, 61-64. De ahora en Adelante se citará RPR (Regulae Patribus Romae)

102 Institutum. S.I. Vol. I, Revisores librorum, XI, in MS, Act 35. 636. especulativa y las controversias filosóficas; en segundo lugar, se creaban los colegios de revisores provinciales -al igual que ya existían en Portugal y España- para revisar otras publicaciones que no entraban en la materialidad de la anterior categoría, sin que ello supusiera fragmentación o independencia, pues siempre estaba el marco común del espíritu jesuita, validado por el Colegio Central de Revisores.

6) El documento consta de quince reglas, muy concretas y precisas, que marcan líneas maestras de actuación y evocan una experiencia muy consolidada. Por su trascendencia $-y$ por el hecho de ser presentadas por primera vez en lengua castellana- merecen mostrarse secuencialmente en su resumen, literalidad y significación.

La regla primera ahonda en el sentido de un colegio central de revisores. Centra su pertinencia en tres argumentos: ayudar al P. General a conservar la doctrina sólida y uniforme en los escritos y en la enseñanza de la Compañía; sus revisores son personas de sensibilidad diversa por su carácter internacional y de consolidado prestigio por su excelente juicio y preparación; finalmente el colegio de revisores va más allá de la propia Compañía: su fin último es ayudar a la conservación y consolidación de la doctrina cristiana en el marco de una sociedad cada vez más abierta. ${ }^{103}$

La segunda regla establece el número de censores. Pueden ser dos, tres o cuatro en función del contenido y orientación de la obra. Dos se asignaban para las obras de "cuestiones más ligeras», eran las que versaban sobre letras humanas e historias profanas; tres para obras que contenían temas filosóficos, discursos para el pueblo, e historias eclesiásticas o sagradas sin controversia; y cuatro para las obras especulativas, las de controversia teológica y las que transmitían doctrina de costumbres. Si en algún caso los revisores resultaban insuficientes, debían comunicarlo al P. General. Todas las obras debían revisarse enteramente. El aumento de revisores con respecto al reglamento de 1601 coincide con el crecimiento de publicaciones internas al que se asiste mediado el siglo XVII. ${ }^{104}$

103 1) Muneris sui gravitatem ex eo metiri Revisores debent, quod Praeposito Generali operam navant in re maximi momento, hoc est, in librorum edendorum examine et censura// Propterea enim ex variis nationibus in unum collecti sunt homines praestanti iudicio et doctrina, ut Generalis, eorum fide diligentiaque adiutus, facilius providere possit, tum caetera, quae in Nostrorum scriptis spectari debent, tum maxime, ut doctrinae soliditas et uniformitas, quam Constituciones requirunt, in Societate conservetur [1)Los Revisores deben valorar la importancia de su oficio por el hecho de que ellos prestan servicio al Prepósito General en un asunto de la máxima importancia, es decir, en el examen y censura de los libros que han de ser publicados // Por esto, en efecto nuestros hombres han sido reunidos de varias naciones en una en función del juicio y formación por el que se distinguen, para que el General pueda tomar medidas más fácilmente, ayudado por el celo y la fidelidad de estos, ya en otros aspectos, los cuales deben ser contemplados en los textos de los nuestros, principalmente para que la solidez y la uniformidad de la doctrina, la cual exigen las Constituciones, sea conservada en nuestra Sociedad] Institutum. S.I. vol. II, RPR: 61-64.

104 2) In libris ergo, quos recognoscendos accipient, ut congruentem pro cuiusque argumento et qualitate curam adhibeant, hoc observabunt, ut eos quidem, qui in theologicis speculativis aut in controversias versantur, morumve doctrinam tradunt, quatuor integrum librum examinent// Quod si quando pauciores forte esse contigerit, P. Generalem moneant, ut quid tunc facto opus sit ipse statuat. // Sacrarum vero litterarum comentarios, qui ex proposito controversias dogmatice non miscent (in his enim quatuor etiam esse debent) que libros, qui sacras aut 
La regla tercera se fijaba en el juicio o calidad de la obra. Cuando la decisión resultaba negativa debía trasmitirse al P. General, sin más preámbulos, para que tomara la decisión correspondiente. Si resultaba positiva, los censores deliberarían sobre las posibles correcciones, el juicio que les merecían las correcciones aportadas por diferentes censores provinciales y las respuestas que el autor daba a estas censuras. ${ }^{105}$

La regla cuarta se refería a la puesta en común de las decisiones. Todos debían justificar y explicar el porqué de sus censuras. El resultado sería un dictamen único, común y representativo. En el mismo, debían omitirse palabras o situaciones que interfiriesen o molestasen a la Inquisición. Se trataba de no inventar novedades o usurpar funciones que asumían la Sagrada Congregación para el Índice, creada en 1572, y los índices de la Inquisiciones locales. ${ }^{106}$

eclesiasticas historias, concionesve ad populum, aut quaestiones philosophicas complectuntur, tres omnino perlegant // Qui vero leviora continent, quam aut a singulis censoribus omnia lege necesse sit, ut, qui in Humanistas litteris, aut profanis versantur historiis, duo saltem integros evolvant: ac tum etiam in his reliqui Revisores partem illorum aliquam inspiciant, quantum nimirum satis sit, ut cum aliis postea conferre, et de libris ipsis iudicare una possint [2) Por consiguiente, en los libros que reciban para ser revisados, con el fin de aplicar una adecuada atención en función de la materia y cualidad de cada uno, observarán esto: que cuatro censores analicen íntegros los (libros) que versen sobre cuestiones de especulación y controversia teológica o transmitan doctrina de costumbres. // Pero si alguna vez sucede que son por casualidad unos pocos de los nuestros, advertirán al P. General, que él decida lo que es preciso hacer entonces.// Por otra parte, los comentarios y los libros de las Sagradas Escrituras, que no mezclan controversias dogmáticas, pues en estos en efecto deben ser examinados también por cuatro censores, y los libros que comprendan historias sagradas o eclesiásticas, o discursos para el pueblo o asuntos filosóficos, los leerán enteramente tres (censores). // Pero los libros que contienen cuestiones más ligeras que, o bien sea necesario que sean leídas por cada uno de los censores, como las que versan sobre las letras más humanas, o las que versan sobre historias profanas, dos (censores) las lean íntegramente.// Y también entonces los restantes revisores examinen alguna parte de aquellos (libros), en la medida en que sea suficiente, con el fin de que posteriormente puedan, juntamente con los otros, hablar y juzgar sobre los mismos libros.] Institutum. S.I. vol. II, RPR: 61-64.

105 3) Iudicium porro illorum duplex erit//. Unum, ut dispiciant, an liber talis sit; qui a Societate in lucem edi iure possit//In quo si edi debere non fuerit iudicatum, non erit quod ulterius progrediantur, sed suum hoc iudicium statim referent ad P. Generalem, ut quod facto opus sit ipse consideret ac statuat// Alterum, ut, cum operae Premium esse duxerint ut edatur, tum de censuris deinceps deliberent, ac definiant, an corrigi liber debeat iuxta ea, quae vel ipsemet observarint, vel ex Provincias missa fortase fuerint.// Quocirca, cum librum aliquem accipiunt recognoscendum, curent, ut simul cum libro tradantur censurae ex Provincia missae, si quae sint, cum responsis auctoris ad censuras. [3) Por otra parte el juicio de aquellos será doble.// Uno será para que examinen si un libro es tal que pueda ser, en justicia, editado por la Compañía//Si no se hubiera llegado al acuerdo de que el libro debe ser editado, no habrá motivo para que lo traten más adelante, sino que trasladarán este juicio suyo inmediatamente al P. General, para que él, personalmente, considere y establezca lo que es preciso hacer.// El segundo (juicio) será para que, cuando hayan considerado que merece la pena que sea publicado, ellos deliberen inmediatamente después sobre las censuras, y determinen si el libro debe ser corregido acerca de esos aspectos que, o bien ellos mismos hayan observado, o bien que hayan sido enviados desde las provincias// En consecuencia, cuando ellos reciban algún libro para ser examinado, procuren que junto con el libro sean entregadas las censuras enviadas desde la provincia, si las hubiera, junto con las respuestas del autor a las censuras.] Institutum. S.I. vol. II, RPR: 61-64.

106 «) In rebus maioris momento conveniens erit, ut prius adducantur rationes in utramque partem;// tum vero procedatur ad ferendum
La regla quinta prescribe que se presenten al P. General la decisión sobre los libros aprobados, el dictamen de las censuras firmadas por todos y el voto particular que algún censor quisiese formular, caso de discrepancia u omisión. En cualquier caso, era el General quien decidirá siempre sobre la decisión y naturaleza de lo presentado. ${ }^{107}$

En la regla seis se concentra buena parte del tema nuclear de la revisión: se refiere a la materia de la censura y a cómo hacerlo. Un punto en el que no hay novedad con lo aportado en el punto tres de las reglas de 1601. Al igual que ahí, remite a los mismos cuatro referentes de la Ratio studiorum: fijarse en las reglas 5 y 6 del capítulo sobre los profesores de facultades superiores; en las reglas 1, 2, 6, 8, 10 y 11 del profesor de Sagrada Escritura; en las 2, 3, 4 y 5 del profesor de Teología escolástica, y en las reglas 2 y 3 del profesor de filosofía. Un depósito referencial que debía conocerse con claridad, hondura y precisión; que buscaba garantizar que toda publicación interna confirmase el espíritu de las Constituciones; y que nada fuese contra axiomas de los Padres de la Iglesia, contra el sentir común de los colegios y contra la fe o devoción cristianas. ${ }^{108}$

ex omnibus auditis iudicium.// Caveant autem in formandis censuris, ne utantur verbis, quae ofendere possint Sacram Inquisitionem: // quod fieret, si proposiciones nulla hactenus a Sacra Inquisitione notatas graviore censura, puta haeresis, errores, temeritatis, et, ipsi damnarent.// Simpliciter itaque censeant ac iudicent de propositionibus, an ea in scholis nostris, aut in libris, qui a Nostris eduntur, permitti debeant.// [4) En asuntos de mayor importancia será conveniente que primero sean aportadas las razones a una y otra parte.// Pero entonces procédase para presentar un dictamen de entre todos los escuchados//. Eviten en la formación de las censuras que no se haga uso de palabras que puedan molestar a la Santa Inquisición: // lo que sucedería si nuestros censores condenaran proposiciones no señaladas por el momento con ninguna censura grave limpia de herejía, error y temeridad por la Santa Inquisición.// Así pues, sencillamente examinen y juzguen acerca de estas proposiciones si esto se debe permitir en nuestros colegios o en los libros que son editados por los nuestros.] Institutum. S.I. vol. II, RPR: 61-64.

107 «5) Absolutis cuiusque libri consultationibus, tum eius libri approbationem, tum censuras Patri nostro subscriptas exhibebunt, ut de his statuat, quod convenire videbitur.// Suscribent quidem omnes, si in eas maior pars consenserit.// Si quis vero, vel in approbatione libri, vel in aliqua censura discrepaverit, vel omissum aliquid fuerit, quod ei dignum censura videatur, separatim id ad P. Generalem cum suis rationibus, vel eodem folio vel diversis, ut placuerit, scribet, si rem dignam iudicaverit, de qua P. Generalis moneatur.// Cum vero paria erunt utrimque sufragia, eae quidem censurae inter communes non ponantur, sed ad Patrem nostrum simul offerendae erunt utriusque partis rationes, ut pro re nata statuat quod expedire iudicabit [5) Concluidas las deliberaciones de cada libro, mostrarán a nuestro Padre, ya la aprobación de este libro, ya las censuras firmadas, para que decida sobre estas cosas que le parezca conveniente.// Más aun, las firmarán todas, si la mayor parte está de acuerdo en ellas.// Pero si alguno de los censores, bien en la aprobación del libro, bien en alguna censura, discrepara, o bien se omitiera algo que le pareciera digno de censura, de manera particular escribirá esto al P. General con sus razones, bien en la misma hoja o en hojas distintas, como mejor le parezca, si piensa que el asunto sobre el cual sea advertido el P. General merece la pena.// Pero cuando los juicios por ambas partes sean iguales, estas censuras no se expondrán a la comunidad sino que las razones de ambas partes serán alegadas a nuestro Padre simultáneamente para que decida de acuerdo con la naturaleza de las circunstancias que juzgará convenientes.] Institutum S.I. vol. II, RPR: 61-64.

108 «6). Censuras librorum ad ea maxime dirigent, quae in Ratione Studiorum praecipiuntur, in Regulis communibus videlicet Praeceptorum Facultatum superiorum 5 et 6; Professoris Scripturae 1, 2, 6, 8, 10 et 11; Professoris scholasticae Theologiae 2, 3, 4, 5; et Professoris Philosophiae 2 et 3 , soliditatem uniformitatemque doctrinae iuxta Constituciones 
La regla siete es un complemento o remache del anterior. Pero con una particularidad muy ilustrativa: rezuma traumas y problemas de la experiencia secular jesuita que no se contemplaban en las reglas de 1601 . Insiste en seis aspectos concretos: a) que en los libros internos no haya novedades o se discrepe de la doctrina común, b) que no se socave aquellos razonamientos comunes que se utilizan para avalar los dogmas de la religión, c) no separarse de Santo Tomás en las doctrinas teológicas, d) no escribir nada que concierna a las leyes de los Príncipes, a su inmunidad, a su jurisdicción y a sus privilegios, e) no tratar asuntos políticos relacionados con personas, cuestiones nacionales o provinciales que puedan traer como consecuencia una justa ofensa ${ }^{109}$, y f) que cuando se escriba sobre herejes se cuide la moderación y se haga con la solidez de la doctrina. ${ }^{110}$

nostras et decretum 55 quintae Congregationis semper intuendo.// Neque in ea re nostrorum scriptorum, sicubi a communi via deflectant, ducantur exemplo, quidquid aliqui e Nostris ante scripserint.// Unde, ut approbetur a Revisoribus opinio aliqua, non sufficit, quod idonei alicuius auctoris sit.// Requiritur insuper, ut non sit contra Doctorum axiomata, que communem scholarum sensum.// Atque, in universo loquendo, non solum admitti nihil debet, quod fideique pietati christianae non prorsus congruat.// Sed neque aliud quidpiam, quod alios merito possit ofendere, vel Societatis existimationem religiosamque circumspectionem dedecere videatur.[6). Ellos dirigirán las censuras de los libros especialmente hacia esas cuestiones que están ordenadas en el Sistema de Estudios, por supuesto en las reglas comunes 5 y 6 de los profesores de las facultades superiores; en las reglas 1, 2, 6, 8, 10 y 11 del profesor de Sagrada Escritura; en las reglas 2, 3, 4 y 5 del profesor de Teología escolástica, y en las reglas 2 y 3 del profesor de filosofía, siempre observando la solidez y uniformidad de nuestra doctrina en lo tocante a nuestras Constituciones y observando el decreto 55 de la quinta Congregación General.// Y no en este asunto de nuestros escritores, si en alguna parte ellos se desvían del camino común, sean tomados como ejemplo, no importando que algunos de los nuestros hayan escrito anteriormente.// Por lo cual, para que alguna opinión sea aprobada por los Revisores, no basta que sea de algún autor de prestigio.// Además se exige que no vaya contra los axiomas de los doctores, y contra el común pensamiento de los colegios.// Por otra parte, hablando en general, nada, que no está de acuerdo absolutamente con la fe y la devoción cristiana, debe ser aceptado.// Ni siquiera debe ser admitida cualquier otra cosa que pueda ofender razonablemente a otros o bien parezca no convenir a la estima y consideración religiosa de la Compañía] Institutum. S.I. vol. II, RPR: 61-64.

109 Algunas de estas prescripciones escondían con diplomacia problemas sociales y casi dispensaban al jesuita de su dimensión secular. Lo cierto es que a mayor abundamiento, la Congregación General V, celebrada en 1594, en sus decretos 47 y 79 [Institutum. S.I. Vol. I, CG. V, d. 47 in MS.:555.; 565 (Decr. 79)], y la Congregación General VII, acaecida en 1646 , en su decreto 46 , prohibieron a los jesuitas ayudar a reyes y gobernantes en asuntos políticos [Institutum. S.I. vol. I, CG. VII, d. 46.: 601.]

110 7). Providebunt itaque: 1 . Ne in libris Nostrorum novae, et a communi doctrina discrepantes opiniones inducantur. 2. Ne comunes rationes, quibus Religiones christianae dogmata confirmant Theologi, convellantur. 3. Ne a D. Thomae doctrina, iuxta Constituciones et Congregationum Decreta, in theologicis discedatur. 4. Ne quid contineant, quod vel ad iura Principium, immunitates, iurisdictionem, et privilegia, vel materiam Status, ut vocant, pertineat, vel alia quavis ratione nationum provinciarumque res aut personas sic attingat, ut iuxta sequi possit offensio.//In iis porro, qui contra haereticos scribunt, observabunt praecipue, an cum doctrinae soliditate stilum ita moderentur, ne plus aequo acerbitatis habere, aut alia ratione levior merito cuiquam videri possit. [7). Así pues, (los censores) procurarán que: 1.- No sean introducidos en los libros de los nuestros opiniones nuevas o discrepantes de la doctrina común. 2.- No se socaven los razonamientos comunes con los cuales los teólogos confirman los dogmas de la religión cristiana. 3. No se aparten de la doctrina de Santo Tomás, en cuestiones teológicas, conforme a las Constituciones y los decretos de las Congregaciones.
La regla octava se centraba en la mejora e innovación que toda publicación debía conllevar. Era un punto especialmente sugerente, insistía en cinco aspectos: a) lo publicado por un jesuita no podría ser una repetición de lo dicho por otros, b) debía ser una aportación e interpretación personal digna de publicarse, c) no podría caer en la mediocridad, d) superaría el término medio de las obras de su género, y e) ratificaría el espíritu hermenéutico de la Compañía de Jesús. ${ }^{111}$

La regla nueve se refería al tono de los escritos. Se trataba de una apuesta por la moderación y la templanza. En concreto, cuando se citase a autores jesuitas debía hacerse con especial deferencia; lejos de discrepar con vehemencia, debían apoyarse sus ideas; en caso de obligado y legítimo disentimiento, debía hacerse con discreción. Una actitud que también debía extenderse a los doctores católicos fuera de la Compañía. ${ }^{112}$

La regla diez indicaba el conducto reglamentario para la recepción y entrega de escritos. Se recibirían únicamente del P. General a través de su secretario. Serían devueltos por esta vía con las correspondientes censuras firmadas y la fecha correspondiente. En ese proceso, si la obra presentaba graves deficiencias formales de origen, los revisores lo comunicarían al P. General para que los censores de provincias, o los mismos provinciales, fuesen advertidos de lo que habían permitido enviar a Roma. Un tema de especial preocupación y denuncia, pues el ethos jesuita siempre debía velar por la obra bien hecha. ${ }^{113}$

4.- No contengan nada que, o bien concierna a las leyes de los Príncipes, a las inmunidades, a la jurisdicción y a los privilegios, o bien concierna, como se suele decir, a la materia política, o bien que se relacione con personas o cuestiones nacionales o provinciales de tal manera que puedan traer como consecuencia una justa ofensa.// Además en estas cosas quienes escriben contra los herejes cuidarán sobre todo en moderar su pluma con la solidez de la doctrina, para que no pueda parecer tener más acritud de la justa o pueda parecer a alguien, de otro modo, con razón demasiado ligero.] Institutum. S.I. vol. II, RPR: 61-64.

111 8). Quodcumque argumentum tractetur, tale sit, ut aedificationi utilitatique futurum censeatur;// et in eo ita versetur auctor, ut non mera eorum, quae ab aliis scripta sunt, repetitio videri queat, sed sua ipse propria, eaque digna luce habeat;// talisque praeterea sit liber, ut mediocritatem in suo genere non mediocriter superet, hominumque de Societatis lucubrationibus iudicio et exspectationi respondeat.// [8). Cualquier tema que se trate sea de tal modo que se piense que será para infundir sentimientos de piedad y utilidad.// Y en este (tema) el autor se conduzca de tal modo que no pueda parecer una mera repetición de las cosas que fueron escritas por otros, sino que él tenga las suyas propias y sean dignas de publicarse.// Y además, que el libro sea de tal calidad que supere, en su género, no mediocremente el término medio y responda a la opinión y deseo de los hombres acerca del pensamiento de la Compañía.//.] Institutum. S.I. vol. II, RPR: 61-64.

112 9). Diligenter quoque animadvertent, ut Nostri de se invicem, ut par est, honorifice loquantur, neque prae se ferant animum ex professo scriptorem ex Nostris ullum eiusque opiniones aut rationes potius impugnandi, quam suma sententiam stabiliendi. // Quod si aliquando ab alicuius peculiari sententia cogantur discedere, id modeste faciant; // similique etiam cautione utantur erga externos Doctores católicos [9]. Escrupulosamente también cuidarán que los nuestros hablen de sí mismos con deferencia, como conviene, y no manifiesten de una manera ostensible la intención de atacar más bien sus opiniones y razones que de apoyar su punto de vista.// Pero si alguna vez están obligados a disentir de la peculiar opinión de alguien, háganlo discretamente.// También hagan uso de la misma precaución respecto a las obras de doctores católicos fuera de la Compañía]. Institutum. S.I. vol. II, RPR: 61-64.

113 10). Nullus librum scriptumve a quoquam recognoscendum accipiet, praeterquam a P. Generali, aut eius nomine a P. Secretario.// Singula deinde recognita eidem P. Generali reddent;// cum his censuras, 
La regla once prescribía mantener el secreto de oficio antes de que los trabajos fuesen publicados. Ningún revisor debía mostrar preferencia por ninguna obra censurada, manifestar opiniones de algún censor, o mantener juicios públicos sobre su trabajo. El secreto sólo podía vulnerarse con la licencia del P. General. Únicamente podían confesar, caso de ser preguntados, que examinaban esta u otra obra. ${ }^{114}$

La regla doce buscaba la convergencia con otras instancias de censura. Principio que se implementaba poniendo a disposición de los revisores bulas y breves pontificios, decretos del Santo Oficio, censuras de otros lugares y experiencias de universidades e inquisiciones locales que permitieran mayor convergencia, claridad y objetividad en la toma de decisiones. Todo ese material lo proporcionaría el Procurador General. ${ }^{115}$

La regla trece hacía referencia a la contabilidad de las censuras. Existiría un libro donde debían recogerse las censuras realizadas, las actas de las sesiones, la diversidad

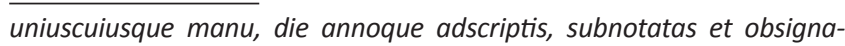
tas.// Quod si contingat, ut liber, qui mittitur recognoscendus, non sit emendate scriptus charactere, qui ab omnibus Revisoribus legi possit, neque sit per suos numeros et paginarum distinctiones ita digestus, ut notari possint loca animadversione digna: id significabunt P. Generali, ut moneantur censores Provinciarum aut Provinciales ipsi, quod huiusmodi Romam mitti permiserint.// [10). Ninguno recibirá de alguien libro o escrito para revisar, a excepción del P. General, o del P. Secretario en nombre de éste. // Después, devolverán cada uno de los documentos revisados al mismo P. General. // Y devolverán las censuras con notas a pie y firmadas junto con estos libros, de mano de cada uno, y fechadas con día y año.// Pero si sucede que el libro que es enviado para ser revisado no ha sido escrito en un estilo correcto, para que pueda ser leído por todos los revisores, ni ha sido ordenado mediante sus números y distinciones de páginas de tal manera que puedan ser anotados los pasajes con una apropiada censura, comunicarán (los revisores) esto al P. General, con el fin de que los censores de las provincias, o los mismos provinciales, sean advertidos que han permitido que estos escritos sean enviados a Roma de esta manera.] Institutum. S.I. vol. II, RPR: 61-64.

114 11). Nec censuras nec scripta, quae recensebunt, priusquam edantur, cuiquam ostendent sine $P$. Generalis facultate, secretique maxime tenaces sint;// ita ut nemini, quae in consultationibus acta sunt, aperiant, multo minus, cuius sententiae hic vel ille fuerit.// Nullius libri scriptive patrocinium suscipient, ita ut evincere velle videantur, neque iudicii sui propensiones aliis ostendent; quamvis, interrogati, respondere possint, se hoc vel illud opus recognoscere. [11). Los censores no enseñarán a nadie, sin el permiso del P. General, ni las censuras ni los escritos que van a examinar antes de que sean publicados y de que hayan sido apartados los más obstinados; // de tal manera que no descubran a nadie estas cuestiones que han sido resultas en las deliberaciones, y mucho menos descubrirán a nadie de qué opinión fue este o aquel censor.//No asumirán la defensa de ningún libro o escrito de manera que parezca que ellos quieren imponerlo, ni mostrarán a otros la propensión de su opinión;// aunque, si son preguntados, puedan responder que examinan esta o aquella obra] Institutum. S.I. vol. II, RPR: 61-64.

115 «12). Pro directione, necesse est, ut bullas et brevia ad doctrinam et mores pertinentia, quae a Summis Pontificibus eduntur, habeant.// Item decreta, quae a sacra Inquisitione, aliisve Congregationibus, et a Magistro Sacri palatii prodeunt./Immo expedirte, ut ea quoque habere curarent, quae alibi ab Inquisitionibus et Universitatibus in eo genere decernuntur: et haec sibi comparari curabunt a Procuratore Generali. [12). A favor de esta dirección, es necesario que los censores tengan las bulas y los breves relativos a la doctrina y costumbres que son publicados por los Sumos Pontífices.// Del mismo modo, es preciso que tengan los decretos que emanan de la Santa Inquisición, o de otras Congregaciones, y del Maestro de la santa Sede.// También, convendría que los censores, del mismo modo, procuraran tener las decisiones que en otro lugar son tomadas, en este sentido, por los inquisidores y las universidades: y procurarán que esto les sea proporcionado por el Procurador General.] Institutum. S.I. vol. II, RPR: 61-64. de opiniones y las razones que las justificaban. Una tarea para la que el Superior podría designar ayudantes. ${ }^{116}$

La regla catorce prescribía guardar en Roma un ejemplar revisado con la correspondiente censura. Serviría, entre otras cosas, para comprobar que la publicación oficial contenía las observaciones de los revisores. Y si por alguna razón se presentasen problemas para la custodia, siempre debía conservarse el escrito de la comisión revisora. ${ }^{117}$

La última regla, la quince -quizá la más novedosa-, prescribía que se crease una comisión censora en las provincias para que los libros, que no fuesen enviados al $P$. General, fuesen revisados con los con los mismos criterios, cautelas y requisitos que en Roma. Con esto se igualaba para todas las provincias el privilegio conseguido en 1604 por España y Portugal. En la desconcentración, los censores pondrían especial celo en cumplir las reglas 6, 7, 8 y 9 del presente documento. Especialmente se insiste en cuidar el anonimato de autores y censores para garantizar mayor libertad de juicio. El Provincial siempre enviaría a Roma las censuras y velaría porque el libro no fuese publicado hasta que no le constase fehacientemente que las correcciones habían sido satisfechas. Las publicaciones del Provincial se someterían igualmente a consulta del P. General. Se advierte que la revisión debía ser completa y llegar a todo el libro: prólogos, prefacios, títulos y advertencias. Y si después de las correcciones el autor quisiera añadir o cambiar algo de importancia, sin el conocimiento de los Superiores, se le advierta que será castigado con severidad en función de la gravedad de la falta. ${ }^{118}$

116 13). Censurarum exempla in libro ad id destinato apud se retinebunt. // Rationes quoque, quibus moti sunt, vel in eodem, vel in alio libro, qui Acta contineat, annotabunt, maxime, si quae fuerit opinionum diversitas, ad memoriam et documentum posterorum.// Quod si necesse erit eos iuvari alicuius alterius opera, id Superiori proponent. [13). Los censores guardarán con ellos copias de las censuras en un libro destinado a este fin. // También anotarán, ya en este mismo libro, ya en otro que contenga las actas, para recuerdo y ejemplo de sus sucesores, las razones por las que se han movido, principalmente si existiera algunas diversidad de opiniones.// Pero si fuera necesario que estos sean ayudados por el trabajo de algún otro, lo propondrán al Superior] Institutum. S.I. vol. II, RPR: 61-64.

117 14). Librorum, qui ab ipsis recogniti et approbati fuerint, exemplaria in Urbe retineri debent, cum censurae in Provincias mittentur;// tum ad alios eventus, tum ut constare posit auctorem nihil postea mutasse, aut edidisse non approbatum.// Quod si hoc servari non potuerit, saltem, loco exemplaris scripti, impressum mitatur Revisoriae, cum censura conferendum, et asservandum [14). Cuando las censuras sean enviadas a las provincias, deben guardarse en Roma ejemplares de los libros que hayan sido examinados y aprobados por ellos (los censores);// ya para otros fines, ya para que pueda quedar constancia de que el autor no ha cambiado nada posteriormente o no ha editado nada que no haya sido aprobado.// Pero si esto no pudiera ser respetado, por lo menos, en lugar del ejemplar escrito, sea enviado el escrito de la comisión revisora, que se ha de reunir y conservar junto con la censura] Institutum. S.I. vol. II, RPR: 61-64.

118 15). Qui designabuntur in Provinciis ad censendos libros, qui forte Romam non mittentur, superiores Regulas habeant, seque, perinde ac generales Romae Revisores, teneri sciant, ut, quae in iis continentur, cautiones omnes in libris examinandis observent:// sed praecipuo quodam studio servare conentur ea, quae praescribuntur superioribus regulis 6,7, 8 y 9.// Qui vero extra ordinem libros edendos a Provinciali accipient, ignoti debebunt esse auctoribus, auctoresque Censoribus, quo maiori cum libertate ac sinceritate iudicare de iis possint.//Etiam hi servent quae aliis supra praescripta sunt, ferantque iudicium, omni seposito humano respectu, solam Dei gloriam ac Societatis bonum prae oculis habentes.// Omnes autem Revisores suas censuras eidem Provinciali 


\section{EL PROBLEMA DE LAS LICENCIAS Y EL CORPUS BIBLIOGRÁFICO}

1) ¿Qué pasó a partir de esas normas? Sencillamente lo que la Curia jesuita pretendía desde la misma fundación de la Compañía: establecer un marco común estable para revisar aquellas publicaciones internas de la Orden. El anhelado deseo de san Ignacio, expresado en el punto 273 de las Constituciones, se había hecho realidad. Las 15 reglas de censura de la X Congregación de 1652 parecían el marco adecuado de ese deseo. De hecho, las Congregaciones Generales que se sucedieron ya no volvieron a dar normativas de calado sobre el tema; se limitaron a recordar el cumplimiento de lo prescrito por el derecho interno de la Orden y a ser las auténticas veedoras de su salud apostólica y misional.

2) Otra cosa muy distinta era que los problemas se erradicaran y no siguieran existiendo. El dinamismo teológico, científico, literario, social, etc. fue de hecho in crescendo, como lo fue también la creación de colegios y los efectivos dedicados a la educación. Un potencial que canalizó su fuerza hermenéutica a través de escritos y publicaciones de distinto tipo, que en muchas ocasiones, por el propio cambio, exigencias y circunstancias particulares, no se sometían a la obligatoriedad de las licencias. A tenor de las denuncias, no parece que esta práctica fuese aislada u ocasional. Las más graves procedían de la propia Orden. Especial significación tienen las denuncias manifestadas

tradent, qui eas Romam ad Generalem mittet; et, cum responsum acceperit, non permittet libros edi, donec illi certo constiterit emendanda esse, quae Generalis emendanda iudicaverit.// Quod si Provincialis ipse aliquid edere volet, id non faciet, nisi consulto prius Generali, servatoque, quem ille praescripserit, ordine.// Porro a Censoribus examinari debebunt, non solum tractus librorum, sed praembula etiam, ac praefationes, admoniciones, epistolae liminares, atque ipsi etiam tituli, ne quidquam indiscussum edatur, omnesque offensionum causae, quantum in nobis erit, praecidantur.// lam, si post correctionem contingeret auctorem aliquid addere vel immutare, insciis Superioribus, quod esset alicuius momento, Superiores id severe, pro gravitate delicti, punire meminerint [15). Quienes sean designados en las provincias para censurar los libros, que en ocasiones no sean enviados a Roma, guarden las reglas anteriores y sepan que están obligados, del mismo modo que los Revisores generales en Roma, a que observen, en los libros que han de examinar, todas las cautelas que en las Reglas se contienen.// Con todo, intentarán prestar atención, con particular empeño, lo prescrito en las anteriores reglas $6,7,8$ y $9 . / /$ Por otra parte, aquellos que reciban del provincial libros destinados a ser publicados de manera extraordinaria, deberán ser desconocidos para los autores y estos desconocidos para los censores, con el fin de que puedan emitir un juicio sobre ellos con mayor libertad y sinceridad.// Además observen estos las reglas que más arriba han sido prescritas para los demás y elaboren su juicio dejada a un lado toda consideración humana y teniendo ante su mirada sólo la gloria de Dios y el bien de la Compañía.// Por otra parte, todos los revisores entregarán sus censuras al mismo provincial, quien las enviará a Roma al Padre General.// y, cuando hayan recibido la respuesta, no permitirá que los libros sean publicados hasta que a aquél le conste con seguridad que ha sido corregido lo que el P. General juzgó que debía ser corregido.// Pero si el propio Provincial quisiera publicar algo, no lo hará sino mediante consulta antes al P. General y respetada la orden que aquél prescribió.// Además, deberán ser examinados por los censores, no sólo el contenido de los libros, sino incluso los prólogos, prefacios, advertencias, cartas iniciales, e incluso los títulos mismos para que no sea publicado nada sin corregir, y sean suprimidos todos los motivos de ofensas en la medida en que esté en nosotros.// Luego, si después de la corrección sucediera que el autor añadiera o cambiase algo, que fuera de alguna importancia, sin el conocimiento de los Superiores, estos habrán de tener presente castigarlo severamente en función de la gravedad de la falta]. Institutum. S.I. vol. II, RPR: 61-64. en el decreto 18 de la XI Congregación General, celebrada en 1661 en relación a la publicación de libros sin licencia. Con dolor y cierta pena, los congregados proponían: «la búsqueda y aplicación de un remedio eficaz para contener con rigor la perniciosa libertad de publicar libros sin licencia, ya sea con su propio nombre, ya con el de otro o, incluso, anónimo. Habiendo sido en esto imaginadas hábilmente y emitidas, por muchos, muchas soluciones, la Congregación se ha puesto de acuerdo, con el más unánime consenso». ${ }^{119}$

3) El tema era muy serio. Para solucionarlo se propusieron cuatro respuestas punitivas de extremada severidad y rigor.

- En primer lugar: «Que se advierta a los autores de las severas y seguras penas a que están expuestos, como supresión del cargo o título, asimismo de palabra activa y pasiva, también de inhabilitación para las dignidades y prelaturas de la Compañía y castigos incluso físicos, que serán determinados al arbitrio del Superior, en función de la gravedad del delito». ${ }^{120}$

- La segunda no era de menor gravedad: «Que estos mismos capítulos de penas se extiendan a los cómplices y confidentes, incluso Superiores, en la misma proporción que [...] hayan cometido falta para ruina y deshonra de la Compañía». ${ }^{121}$

- La tercera revisaba el concepto de publicación y decía: «Que deben ser también comprendidos en la denominación de libros los opúsculos y hojas que se vienen en llamar volantes y, en fin, cualquier impreso que se ofrece a la luz pública». ${ }^{122}$

- La última prescripción incluía como cómplices de la acción a los que intentaban difundir dichos escritos en el extranjero: «Que se decida mantener la presunción de engaño doloso contra aquellos de quienes los extranjeros propaguen los escritos recibidos». ${ }^{123}$

4) ¿Produjeronestasadvertencias los efectos esperados? La verdad es que denuncias tan graves no volvieron a plantearse. Las sucesivas Congregaciones insistieron en el cuidado de las revisiones y petición de licencias a la vez que denunciaban otro tipo de conculcaciones y problemas menores. Resulta revelador lo prescrito en el decreto

119 Propositum est Congregationi ab ipso P. Vicario: de quaerendo parandoque efficaci remedio ad fortiter comprimendam perniciosam libertatem edendorum librorum sine facultate, seu proprio, seu alieno, aut etiam supreso nomine. In quo, cum multa a multis essent solerter excogitata et inter opinandum adducta, convenit Congregatio communiore consensu in ea, quae sequuntur. (Institutum. S.I. vol. I, d. 18: 641).

$120 U t$ in auctores animadvertatur gravibus certisque poenis incurrendis; puta, privatione officii, vocis item activae et passivae, inhabilitate etiam ad dignitates et praelaturas Societatis, poenis etiam corporalibus, pro delicti gravitate Superioris arbitrio decernendis. (Institutum. S.I. vol. I, d. 18, I: 641).

121 Ut haec ipsa poenarum capita ad complices et conscios, etiam Superiores, ea proportione extendantur, qua ipsi magis minusve, vel scriptoris concilia promovendo, vel eadem non revelando, vel ex officio non impediendo, in praesentem Societatis perniciem dedecusque peccaverint. (Institutum. S.I.vol. I: 641).

${ }^{122}$ Ut librorum nomine intelligi etiam debeant libelli et folia, ut vocant, volantia, ac demum quidquid praelo ad publicam lucem committitur. (Institutum. S.I.vol. I, 641).

${ }^{123}$ Ut praesumptio fraudes contra illos stare censeatur, a quipus acepta scripta externi vulgaverint. (Institutum. S.I. vol. I: 641). 
noveno de la XV Congregación General, celebrada en 1706, que recuerda cumplir con lo prescrito en la regla novena de los Revisores Generales de 1652, referida a la moderación y templanza. Los congregados denunciaban que algunos escritores de la Compañía, provocados por las calumnias de sus adversarios, hacían uso de un estilo más agresivo de lo que era común en personas religiosas. Por este motivo prohibían que se publicase cualquier escrito en las imprentas de la Orden que pecase de agresividad, tuviese intemperancia o falta de modestia. Para ello recordaban que nada debía publicarse sin antes haber sido aprobado y revisado detenidamente. ${ }^{124}$

5) La XVI Congregación General, celebrada entre noviembre de 1730 y febrero 1731, fue la última que abordó temas de entidad relacionados con la censura. A los congregados les preocuparon tres temas:

- En el decreto decimoquinto se recuerdan dos cosas ya prescritas por la regla XV de los Revisores: la necesidad de que los censores designados por los superiores fueran desconocidos para los autores, y viceversa; y que los censores lean y tengan muy presentes las Reglas de los Revisores Generales. ${ }^{125}$

- El decreto decimocuarto es una llamada al espíritu de la censura opinionum. Los congregados denunciaban que algunos superiores manifestaban cierta relajación en determinadas tesis y postulados colegiales, argumentando que en sus colegios no había Prefecto de Estudios. Una situación irregular que se zanjó prescribiendo que en aquellos colegios en los que no existiese Prefecto de Estudios las tesis que se propagasen fuesen revisadas por el Prefecto de Estudios del Colegio más cercano. ${ }^{126}$

- Finalmente está el decreto decimotercero. Su tenor es desuma trascendencia, prescribía que los Procuradores, siempre que se reunieran en Congregación, llevaran a Roma los títulos de todos los libros publicados en su

124 Relatum fuit ad Congregationem: quosdam e scriptoribus nostris, adversariorum calumniis provocatos, nonnunquam uti stilo acerbiore, quam viros religiosos decere videatur. Quapropter unanimi consensu declaratum fuit: omnino contra mentem Societatis esse hiusmodi stilum, omnemque talem lucubrationem Nostrorum, qua lectores iure offendi possint. Ad cavendam proinde omnem offensionem, Congregatio decreta omnia et ordinationes, quae aliquando sunt factae pro Revisoribus librorum, confirmat et extendi, quoad praesens punctum, etiam ad theses et folia quaecumque; ne quid omnino typis vulgetur a Nostris, nisi a Revisoribus ad id constitutis approbatum. (Institutum. S.l.vol. I, d. 9: 678)

125 Ad coercendam nimiam librorum in lucem edendorum facilitatem, PP. Deputati, quorum iudicium Congregatio ratum habuit, censuerunt observanda esse sequentia: designati a Superioribus Censores ignoti sint auctoribus, et auctores Censoribus. Legant isti, antequam censuram aggrediantur, Regulas Revisorum generalium, et quae ibi praescribuntur in libris examinandis diligenter observent; ferantque iudicium, omni seposito humano respectu, solam Dei gloriam ac Societatis bonum prae oculis habentes. Curent denique Superiores, atque in primis ipse Provincialis, ut iudicium Censorum exsecutioni mandetur, et liber non prodeat, nisi ad censuram latam exactus. (Institutum. S.I. vol. I, d. 15: 682).

126 Quaesitum fuit: a quo recognoscendae sint theses propugnandae in Collegiis, in quipus nullus est Studiorum Praefectus. Censuerunt Patres: eas recognoscendas a Praefecto generali Studiorum Collegii vicinioris, si tamen aliter non fuerit a Provinciali provisum. (Institutum. S.I. vol. I, d. 14: 682).
Provincia desde la última Congregación General. Los títulos debían aportar el lugar de edición, nombre del impresor, autores fallecidos y los títulos de los libros manuscritos por éstos. ${ }^{127}$ Una vía que empezó a consolidar un viejo anhelo de la Compañía: crear una biblioteca de autores jesuitas que computara la aportación real de la Orden al depósito de la cultura escrita.

6) Resulta difícil cuantificar el número de publicaciones jesuíticas, pero sí se sabe que fue muy importante y considerable. Basta conocer los repertorios que al respecto ha publicado la Compañía de Jesús. Uno de los primeros fue el trabajo de Pedro Ribadeneira (1526-1611), Illustrium scriptorum religiones Societatis lesu catalogus (Amberes, 1608) donde nos muestra los temas y las obras publicadas por los hijos de San Ignacio. A partir de entonces, los intentos por crear una bibliografía de escritores jesuitas será casi una constante. Felipe Alegambe (1592-1652) continuará el intento de Ribadeneira escribiendo: Biblioteca scriptorum Societatis lesu (Amberes, 1643). A su muerte, se reavivó el intento y el 16 de marzo de 1669, el P. General ordenaba a los Superiores que remitiesen listas con las publicaciones jesuitas de sus Provincias. ${ }^{128}$

7) En un ambiente proclive a estos intentos, en el siglo XIX se suscitaron respuestas positivas desde las Asistencias locales. Para Austria, Juan Nepomouceno Soeger publicaba en 1856: Scriptores Provinciae Austriacae Societatis lesu ab eius origine ad nostra usque temporum. Para Polonia, José Brown publicaba en 1862: Biblioteca pisarzow Assystencyi polskiéj towarzystwa jezusowego. Lo mismo ocurría en Britania con el reverendo Oliver, quien en 1845 publicaba: Collections towards illustrating the biography of de Scotch, English and Irish member of the Society of Jesus. Estos intentos locales intentaron ser superados con una obra general de toda la Compañía. Proyecto que entre 1853 y 1861 intentaron los hermanos Luis y Agustín Backer, que en esos años publicaron en Lieja: Biblioteque des écrivants de la Compagnie de Jesús ou noticie bibliographiques. Proyecto que se cerró exitosamente con Carlos Sommervogel (1834-1902), quien en nueve volúmenes publicó una obra monumental sobre los escritores de la Compañía de Jesús: Bibliothèque de la Compagnie de Jésus. (Bruselas/Paris, 1890-1900). Los españoles, desde una perspectiva local, hemos hecho un acercamiento al tema con los trabajos de José Eugenio de Uriarte y Mariano Lecina con la Biblioteca de escritores de la Compañía de Jesús. (Madrid, Imprenta Grafía Universal, 1929-1930).

8) Los títulos que contienen estas colecciones, en términos cuantitativos y de variedad, sencillamente son impresionantes. Desde temas históricos, de espiritualidad, teología dogmática y moral, saberes sermonicales, físico-

127 Ut Bibliothecae Autorum Societatis, quando edenda videbitur, in promptu sit materia: statutum fuit, ut quotiescumque cogetur Congregatio Procuratorum, isti Roman afferant librorum in sua Provincia ab ultima Congregatione editorum títulos, locum editionis, nomen Typographi, \& Autorum defunctorum elogia: títulos ítem librorum manuscriptorum, quos nostri vita suncti relinquunt. Decr. XIII, Congr. XVI. (Institutum. S.I vol. I: 682).

128 ARSI, Epistolae Nostrorum, T. 116, Epistolae comunes (16451727), Romae: 161-162. 
matemáticos, humanistas, cuestiones político-sociales, estéticas, arquitectónicas, musicales y un largo etcétera de temas varios, confirma que la Compañía de Jesús se implicó en el mundo, e hizo de la cultura escrita un cauce misional y apostólico de primera magnitud. Difícilmente puede encontrarse en la Historia de la Iglesia otra Orden que produjera tantos títulos y dedicara tantas energías a la producción escrita. Desconocemos cuánto de la misma pasó por el visto bueno de los superiores de la Orden. A tenor de las críticas, algunas obras no lo hicieron, pero también hay que preguntarse si ello se debió a temas espurios o simplemente el dinamismo productivo de los miembros de la Compañía y las exigencias mismas de los colegios y del apostolado misional superaba las exigencias formales que las licencias conllevaban.

\section{A MODO DE CONCLUSIÓN}

1) Después de este recorrido la pregunta que cabe formularse es si puede establecerse una sistemática censora de la Compañía de Jesús en la Edad Moderna. La respuesta es sí. La Compañía entendió la censura como un medio de afirmación y actualización de la vocación jesuita en el marco de las realidades y circunstancias concretas. No puede olvidarse que la identidad de la Orden se define por ser una institución de la Iglesia católica de carácter espiritual, su fin último era la mayor gloria de Dios y provecho de las almas; que esa aspiración era eminentemente pedagógica, se actualizaba por la unión: letras, virtud, doctrina; que tenía un carácter filológico, por la relación connatural entre pensamiento lenguaje y educación; y que se desenvolvía en una unidad o colegialidad vertical, que aspiraba a respetar la libertad de las conciencias, pues sin libertad y responsabilidad personal no es posible la educación o santificación personal, meta última de todo jesuita.

2) En ese marco identitario tuvo un valor fundamental el principio de obediencia ciega. Una virtud capital que entendía las órdenes de los superiores como mandatos procedentes de la voluntad divina. Una máxima, consideraba una gracia especial de Dios, que llevaba a los inferiores a poner su total inteligencia y voluntad en el cumplimiento fiel y responsable de los mandatos. El resultado fue una colegialidad vertical que, a pesar de los problemas y dificultades que conllevaba, ensalzó el sentido positivo de la censura y convirtió a la Compañía de Jesús en uno de los referentes eclesiales más cualificados de la censura moderna.

3) Este principio identitario tuvo una actualización extra y ad intra con diferente alcance, intensidad y temporalización. La dimensión ad extra se centró en la colaboración con la Iglesia para contrarrestar la herejía protestante, afianzar las buenas costumbres y afirmar una cultura social cristiana. La implementación de este proyecto contó con el apoyo de tres pilares determinantes. En primer lugar, el apoyo del papado. Destacó inicialmente Paulo III, que no sólo aprobó la Orden en 1540, sino que le dio los primeros privilegios, vivae vocis oraculo, para censurar obras heréticas y entrar en contacto con los protestantes; no menos importante fue Pío V, que permitió impulsar las imprentas jesuitas, sus publicaciones internas, a la vez que posibilitó aumentar sus bibliotecas; aunque fue Gregorio XIII, con el breve Exponi nobis, 1575, quien fortaleció su reconocimiento eclesial, dotó a la Compañía de nuevos privilegios censores, le dio más autonomía y la convirtió en uno de los principales baluartes de labor reformadora de la Iglesia. Una tarea que se vio facilitada por un segundo pilar: el referente de la Sagrada Congregación del Índice, 1572. Sus directrices y sus trece índices prohibitorios, elaborados a lo largo de la Edad Moderna, guiaron buena parte de la labor censora ad extra de la Compañía de Jesús. Finalmente cabe destacar la colaboración con las Inquisiciones locales y las autoridades civiles. Una colaboración que permitió elaborar una serie de trabajos que formaron parte de la teoría censora de la Compañía de Jesús. En ese acervo destacan el Memorial de algunos apuntamientos tocantes al catálogo de libros prohibidos y expurgados, escrito por el jesuita Diego Álvarez, en torno a 1600, el De iure et more prohibendi expurgandi et abolendi libros haereticos et noxios, publicado en 1603, por el jesuita Jacobo Gretser, o los Erotemata de bonis ac malis libris publicado en 1653 por el P. Thèophile Raynaud.

4) La censura ad intra se afrontó en un doble plano: la llamada censura opinionum, encaminada a la construcción, dirección, verificación e implementación de las ideas y opiniones pedagógicas; y la llamada censura librorum, un intento por afirmar la identidad jesuita mediante la supervisión, vigilancia, juicio y veredicto de la propia producción escrita. El primer aspecto tuvo una dimensión más periférica y descentralizada, se dinamizó desde las realidades colegiales diversas y buscó su realización práctica a través de cuatro cauces pedagógicos recurrentes: los expurgos, los florilegios, la selección de autores y la experiencia pedagógica acumulada. La censura de los libros fue más centralizada y uniforme en atención a la filosofía de los puntos 273, 274 y 653 de las Constituciones ignacianas. Ahí se sostenían los principios esenciales de una colegialidad vertical que demandaban la convergencia y la unidad. Principios que se articularon a lo largo del tiempo, con ciertas dificultades, en los colegios centrales y provinciales de revisores. Una apuesta por una unidad que, aunque planteó dificultades y disensos, puede decirse que fue una realidad patente y meridiana hasta el punto de convertir a la Compañía de Jesús en una de las instituciones más influyentes en la configuración de la cultura moderna.

\section{BiBLIOGRAFÍA}

Astrain, A. 1912. Historia de la Compañía de Jesús en la asistencia de España, Madrid: Razón y fe.

Baldini, U. 1985. «Una fonte poco utilizatta per la storia intellectuale: le censurae librorum e opinionum nell'antica Compagnia de Gesu». Annali dell'Istituto Storico Italo-Germanico in Trento XI: 19-67.

Baldini, U. 1992. Legem impone subactis. Studi su filosofia e ciencia dei gesuiti in Italia (1540-1632). Roma: Bulzoni Editore.

Bertrán Quera, M. 1984. La Pedagogía de los jesuitas en la Ratio Studiorum. La fundación de colegios. Orígenes, autores y evolución histórica de la Ratio. Análisis de la educación religiosa, caracterológica e intelectual. Caracas (Venezuela): Ed. Arte.

Biasiori, L. 2010. «Il controllo interno della produzione libraria nella Compagnia di Gesù e la formacione del Collegio dei Revisori generali (1550-1650)», en Censura, riscrittura, restauro: 221-251. Pisa: Annali della Scuola Normale Superiore di Pisa.

Bujanda, J. M. de. 1985. "Index de I'Université de Paris: 1544, 1545, 1547, 1549, 1551, 1556», en par J.M. De Bujanda, J. M.; Higman, F.; James, K. Sherbrooke: Centre d'Études de la Renaissance. 
Bujanda, J. M. de. 2002. Index librorum prohibitorum: 1600-1966. Montréal: Librairie Droz.

Bujanda, J. M. de. 2016. El Índice de libros prohibidos y expurgados de la Inquisición española (1551-1819). Madrid: BAC.

Cereceda, F. 1950. «Episodio inquisitorial de San Francisco de Borja». Razón y Fe CXLII: 174-191, 355-366.

Danieluk, R. 2004. L'écriture de l'histoire de la Compagnie de Jésus: L'œuvre bibliographique de Carlos Sommervogel (1890-1932).

Fabre, P. A. 1995. "Dépouilles d'Egypte. L' expurgation des auteurs latins dans les collèges jésuites», en L. Giard (dir): Les jésuites a la Renaissance. Système éducatif et production du savoir. Paris: Presses Universitaires de France.

Fernández Collado, Á. 1991. Gregorio XIII y Felipe II en la nunciatura de Felipe Sega (1577-1581): aspectos político, jurisdiccional y de reforma. Toledo: Estudio Teológico de San Ildefonso.

Gagliardi, D. 2010. "La teoría de la censura en el Theotimus de Putherbeus», en Vega Ramos, M. J.; Esteve, C. (eds.): Reading and censorship in early modern Europe: 25-38. Barcelona: Universitat Autònoma de Barcelona, Servei de Publicacions.

García Hernán, E. 2010. «El ambiente alumbrado y sus consecuencias en la Compañía de Jesús según Jerónimo Nadal». Revista de Historia "Jerónimo Zurita» 85: 193-206.

Gattoni, M. 2007. Gregorio XIII e la politica iberica dello Stato pontificio (1572-1585). Roma: Studium.

Girolami Cheney, L. de. 2005. Le imprese del drago: Politica, emblematica e scienze naturali alla corte di Gregorio XIII (1572-1585). Rome: Bulzoni Editore.

González Novalín, J. L. 1990. «La Inquisición y los Jesuitas (s. XVI)». Anthologica Annua 37: 11-57.

González Novalín, J. L. 1994. "La Inquisición y la Compañía de Jesús (1559-1615)». Anthologica Annua 41: 77-103.

González Novalín, J. L. 2001. «Inquisición», en Diccionario Histórico de la Compañía de Jesús: 2028-2038. Madrid: Universidad Pontificia de Comillas.

Gretser, (S.I.) 1603. De iure et more prohibendi expurgandi et abolendi libros haereticos et noxios aduersus Franciscum lunium
Caluinistam \& Ioannem Pappum aliosq[ue] praedicantes Lutheranos. Ingolstadii: ex Officina Typographica Ederina, per Andream Angermarium.

Lukács, L. 1958. "De prima societatis ratione studiorum, sancto Francisco Borgia praeposito generali constituta (1565-1569)», en Archivum Historicum Societatis lesu, vol. 27: 209-232.

Lukács, L. 1960. "De origine collegiorum externorum deque controversiis circa eorum paupertatem obortis, pars I: 1539-1556», en Archivum Historicum Societatis lesu, vol. 29: 189-245.

Lukács, L. 1961. "De origine collegiorum externorum deque controversiis circa eorum paupertatem obortis, pars II: 1557-1608», en Archivum Historicum Societatis lesu,, vol. 30: 1-89.

Matei, F. y Casalini, C. 2014. Jesuitica Institutio. Figure e temi di una modernità pedagogica: 162-163. Roma: Editoriale Anicia srl.

Moreno Martínez, D. 2013. «La aportación española al debate sobre la obediencia ciega en la Compañía de Jesús durante el Papado de Sixto IV (1585-1590)». Investigaciones Históricas: Época Moderna y Contemporánea 33: 63-88.

Moreno Martínez, D. 2015. «Los jesuitas, la Inquisición y la frontera espiritual de 1559». Bulletin of Spanish Studies: Hispanic Studies and Resarch of Spain, Portugal and Latin American 92, № 5: 655-675.

O’Malley, J. W. 1999. Los primeros Jesuitas: 147. Santander: Sal terrae. Putnam, G. 2003. Censorship of the Church of Rome and Its Influence Upon the Production and Distribution of Literature vol. 1: 189-193 Kessinger.

Ruiz Jurado, M. 2001. «Constituciones», en Diccionario histórico de la Compañía de Jesús. Biográfico- temático: col. 928-934. Madrid: Universidad Pontificia de Comillas.

Santonja, P. 2001. La herejía de los alumbrados y la espiritualidad en la España del siglo xvI. Inquisición y sociedad. Valencia: Generalitat Valenciana. Colección Ideas.

Scaduto, M. (S.I.) 1955. «Laínez e L'índice del 1559. Lullo, Sabunde, Savonarola, Erasmo». AHSJ 24: 3-32. 